NASA TECHNICAL NOTE

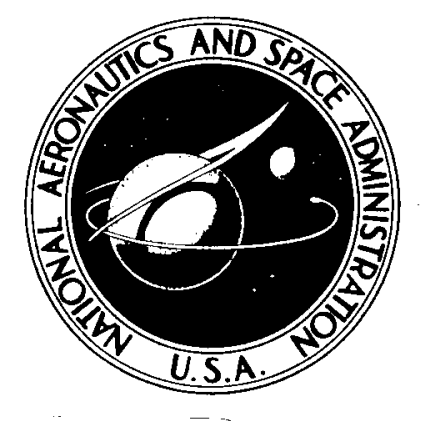

NASA TN D-3250

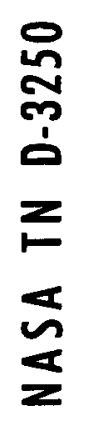
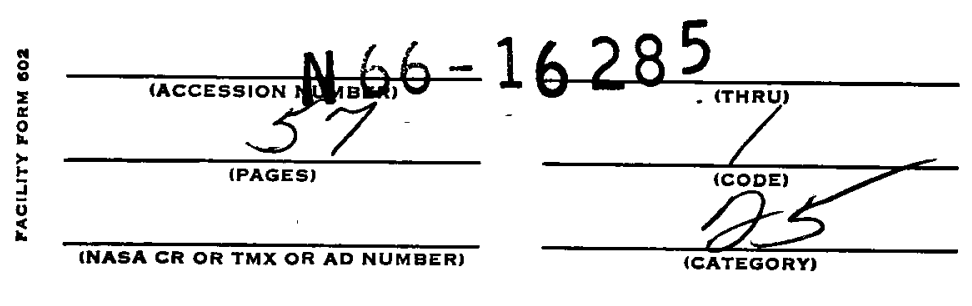

GPO PRICE \$

CFSTI PRICE(S) \$ 3. $\mathrm{O} C$

Hard copy (HC)

Microfiche (MF)

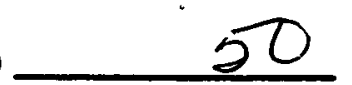

f 853 July 65

\title{
BASIC STUDIES OF A LOW DENSITY HALL CURRENT ION ACCELERATOR
}

by Donald L. Cbubb and George R. Seikel

Lewis Research Center

Cleveland, Obio

NATIONAL AERONAUTICS AND SPACE ADMINISTRATION • WASHINGTON, D. C. • FEBRUARY 1966 
By Donald L. Chubb and George R. Seikel

Lewis Research Center

Cleveland, Ohio 


\section{CONTENTS}

Page

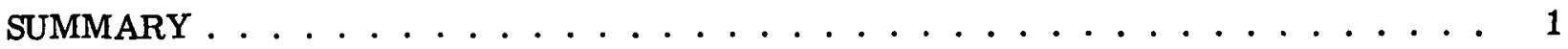

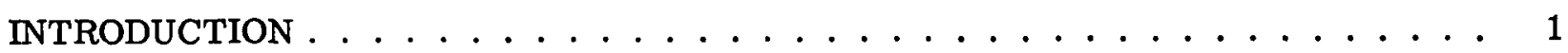

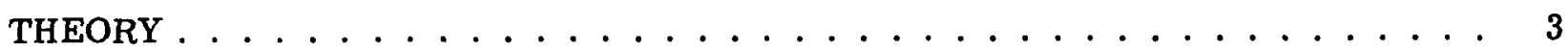

Classical Analysis . . . . . . . . . . . . . . . . . . 3

Anomalous Diffusion Analysis . . . . . . . . . . . . . . . . . 9

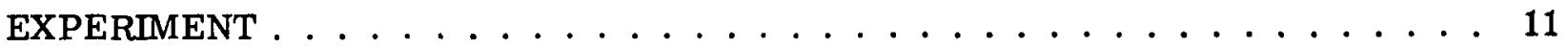

Apparatus ............................. 11

Discharge Operation . . . . . . . . . . . . . . . . . . . 12

DIAGNOSTIC METHODS AND EQUIPMENT. . . . . . . . . . . . . . . . . . . . 13

Langmuir and Emitting Probes . . . . . . . . . . . . . . . . . . . . 13

Hall Current Measurement . . . . . . . . . . . . . . . . . . 17

Button Probe ........................ . . 18

Neutral Number Density Measurement . . . . . . . . . . . . . . . . 18

RESULTS AND DISCUSSION . . . . . . . . . . . . . . . . . . . . . 20

Electron Distribution Function . . . . . . . . . . . . . . . . . . 20

Experimental Variation of Plasma Properties Through Accelerator . . . . . . . 21

Experimental Evidence of Anomalous Diffusion . . . . . . . . . . . . . . 26

Dependence of Plasma Properties on Magnetic Field . . . . . . . . . . . . . 29

Experimental ....................... 29

Theoretical ......................... . . 30

Experimental Accelerator Efficiency . . . . . . . . . . . . . . 32

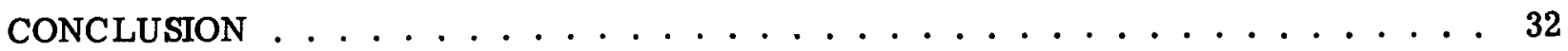

APPENDIXES

A - SYMBOLS ........................... . . . 34

B - ELECTRON EQUATION OF MOTION . . . . . . . . . . . . . . . . . 36

C - ELECTRON ENERGY EQUATION . . . . . . . . . . . . . . . . . . 45

REFERENCES ............................ 53 


\title{
BASIC STUDIES OF A LOW DENSITY HALL CURRENT ION ACCELERATOR
}

\author{
by Donald L. Chubb and George R. Seikel \\ Lewis Research Center

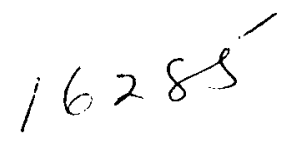

SUMMARY

An experimental and theoretical investigation of a low density annular Hall current ion accelerator operating with argon gas was carried out. The variation of electron temperature and number density, ion current density, and plasma potential through the accelerator were experimentally determined as a function of the magnetic field strength. Azimuthal electron Hall current was also measured. Experimentally determined values of the axial electron current density parallel to the applied electric field were much larger than those predicted by classical electron diffusion, and the ratio of the azimuthal Hall current to the axial current was much smaller than expected. As a result, it was concluded that an anomalous electron diffusion mechanism exists.

The variation of the electric field with magnetic field could be reasonably predicted by an anomalous electron diffusion analysis that made use of the experimentally determined value of the Hall parameter (electron cyclotron frequency/electron collision frequency). The experimental results indicate that energy and momentum transfer to the accelerator walls are the primary loss mechanisms for the accelerator.

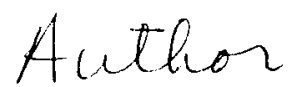

\section{INTRODUCTION}

Hall current ion accelerators are currently receiving considerable research attention. The use and performance of such accelerators have been discussed by several authors for the low density regime (refs. 1 to 4). This regime is defined as that for which the mean free path for ion-neutral collisions is much larger than the characteristic length of the accelerator. Hall accelerators that operate in a higher density range where ion-neutral collisions are important, have also been studied (ref. 5).

The annular Hall ion accelerator to be considered here is illustrated in figure 1. Operation of the accelerator with argon gas was investigated. A radial magnetic field was produced between an inner iron core and an outer iron ring by a coil wound around the inner core. An axial electric field, which accelerates the ions, is established be- 


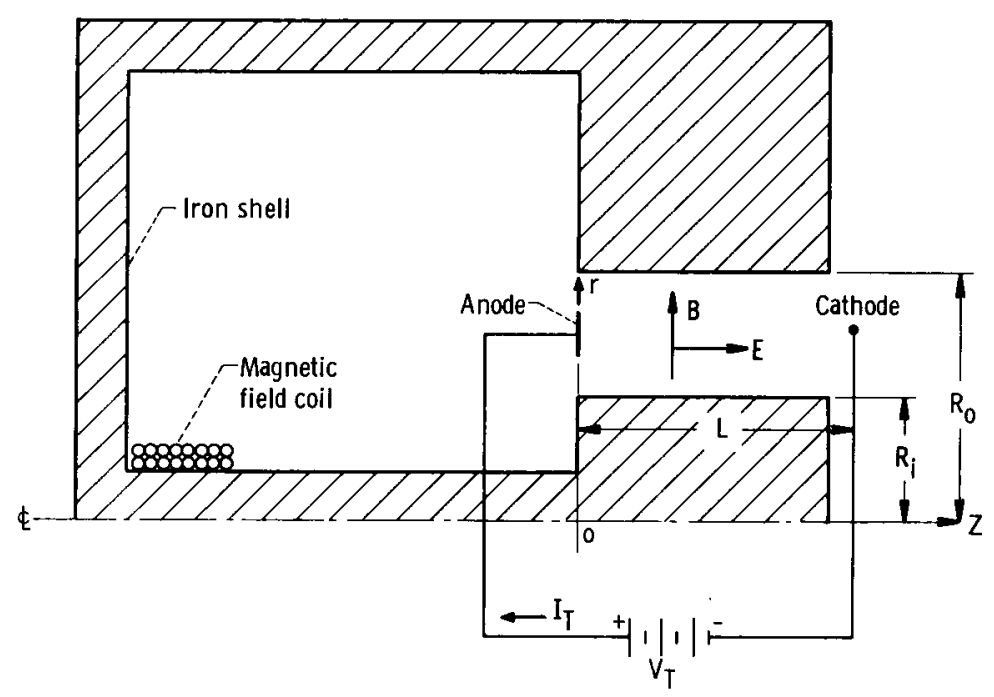

Figure 1. - Annular Hall current ion accelerator.

tween the cathode and anode. The perpendicular electric and magnetic fields establish an azimuthal electron current. Since this current is perpendicular to the applied electric and magnetic fields, it can be called a Hall current. It is from this that the accelerator: derives its name.

Operation of the discharge is maintained by nonequilibrium ionization of the neutral argon atoms through collisions with high energy electrons. The electron temperature must be high enough to maintain a balance between the ion loss rate and the ion produc-. tion rate. Ion losses are those to the walls as well as to the accelerated ion beam. The elevated temperature is maintained by joule heating of the electron gas.

Both a theoretical and an experimental study were carried out for this type of annular accelerator. The experimental program was directed at understanding the physics of the accelerator rather than measuring overall characteristics such as thrust. As a result, local macroscopic properties such as number density, electron temperature, and plasma potential were measured. From this information conclusions could be drawn concerning electron diffusion across the magnetic field and the ion acceleration process. Also, the dependence of the accelerator performance on the magnetic field could be established. Probe techniques were employed to determine the plasma properties. From the measured properties an approximate acceleration efficiency was computed.

The theoretical analysis was used to establish the dependence of the electric field on the magnetic field. In making the analysis, the effect of inelastic processes (ionization and excitation) was considered; however, energy loss to the accelerator walls was not considered. 


\section{THEORY}

\section{Classical Analysis}

In analyzing the annular Hall ion accelerator, a combination of the electron continuity and momentum equations was employed. The electron energy equation that was used included ionization and excitation. Such an analysis is similar to the methods commonly applied to the positive column in a magnetic field (ref. 6).

In appendix $\mathrm{B}$ the following equation of motion for electrons is developed (eq. (B15))

$m_{e}\left(\vec{u}_{e} \cdot \nabla\right) \vec{u}_{e}+\frac{\nabla p_{e}}{n_{e}}+q\left(\vec{E}+\vec{u}_{e} \times \vec{B}\right)=-\left[\frac{m_{e} m_{o}}{m_{e}+m_{o}} \nu_{e o}\left(\vec{u}_{e}-\vec{u}_{o}\right)+\frac{m_{e} m_{i}}{m_{e}+m_{i}} \nu_{e} i_{m}\left(\vec{u}_{e}-\vec{u}_{i}\right)\right]$

where the subscripts $e, o$, and $i$ refer to the electrons, neutrals and ions, respectively, and $q$ is the magnitude of the charge of an electron $\left(q_{e}=-q\right.$ ). (All symbols are defined in appendix A.) The quantities $\nu_{\mathrm{eo}}$ and $\nu_{\mathrm{ei}}$ are the momentum transfer collision frequencies for electron-neutral and electron-ion collisions and are given in appendix $B$ by equations (B17) and (B18).

The following approximations were made in obtaining equation (1):

(1) The contribution to momentum transfer from inelastic collisions has been neglected.

(2) Maxwellian velocity distributions have been assumed for the electrons, ions, and neutrals.

(3)

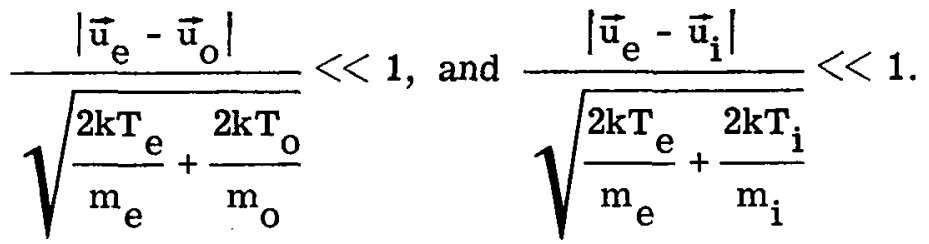

(4) Steady state exists, $\partial / \partial t=0$.

Making the following assumptions

(1) The accelerator exhibits azimuthal symmetry $\left(\partial / \partial \theta=0\right.$ and $\left.E_{\theta}=0\right)$

(2) Induced magnetic fields are negligible, therefore, only the applied radial field exists $\left(\vec{B}=\overrightarrow{B i}_{r}\right)$

(3) Radial variations in velocity are negligible

(4) $\mathrm{u}_{\mathrm{o}_{\theta}}<<\mathrm{u}_{\mathrm{e}_{\theta}}$

(5) $\mathrm{m}_{\mathrm{e}}<<\mathrm{m}_{\mathrm{o}} \approx \mathrm{m}_{\mathrm{i}}$

gives equation (1), in scalar form, as 
r-direction:

$$
u_{e_{r}}\left(1+\frac{\nu_{e i}}{\nu_{e o}}\right)=\frac{1}{\nu_{e o_{m}}}\left(\frac{u_{e_{\theta}}^{2}}{r}-u_{e_{z}} \frac{\partial u_{e}}{\partial z}\right)-\frac{1}{m_{e} n_{e}{ }_{e o}} \frac{\partial p_{e}}{\partial r}-\frac{q}{m_{e} \nu_{e o}} E_{r}+u_{i_{r}} \frac{\nu_{e} i_{m}}{\nu_{e o}}+u_{o_{r}}
$$

$\theta$-direction:

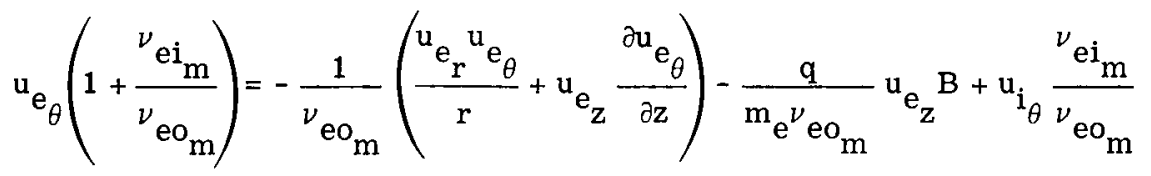

z-direction:

$$
u_{e_{z}}\left(1+\frac{\nu_{e i}}{\nu_{e o_{m}}}\right)=-\frac{1}{\nu_{e o_{m}}}\left(u_{e_{z}} \frac{\partial u_{e}}{\partial z}\right)-\frac{1}{m_{e} n_{e} \nu_{e o}} \frac{\partial p_{e}}{\partial z}-\frac{q}{m_{e} \nu_{e o}}\left(E_{z}-u_{e_{\theta}} B\right)+u_{i_{z}} \frac{{ }_{e i} m}{\nu_{e o}}+u_{o_{z}}
$$

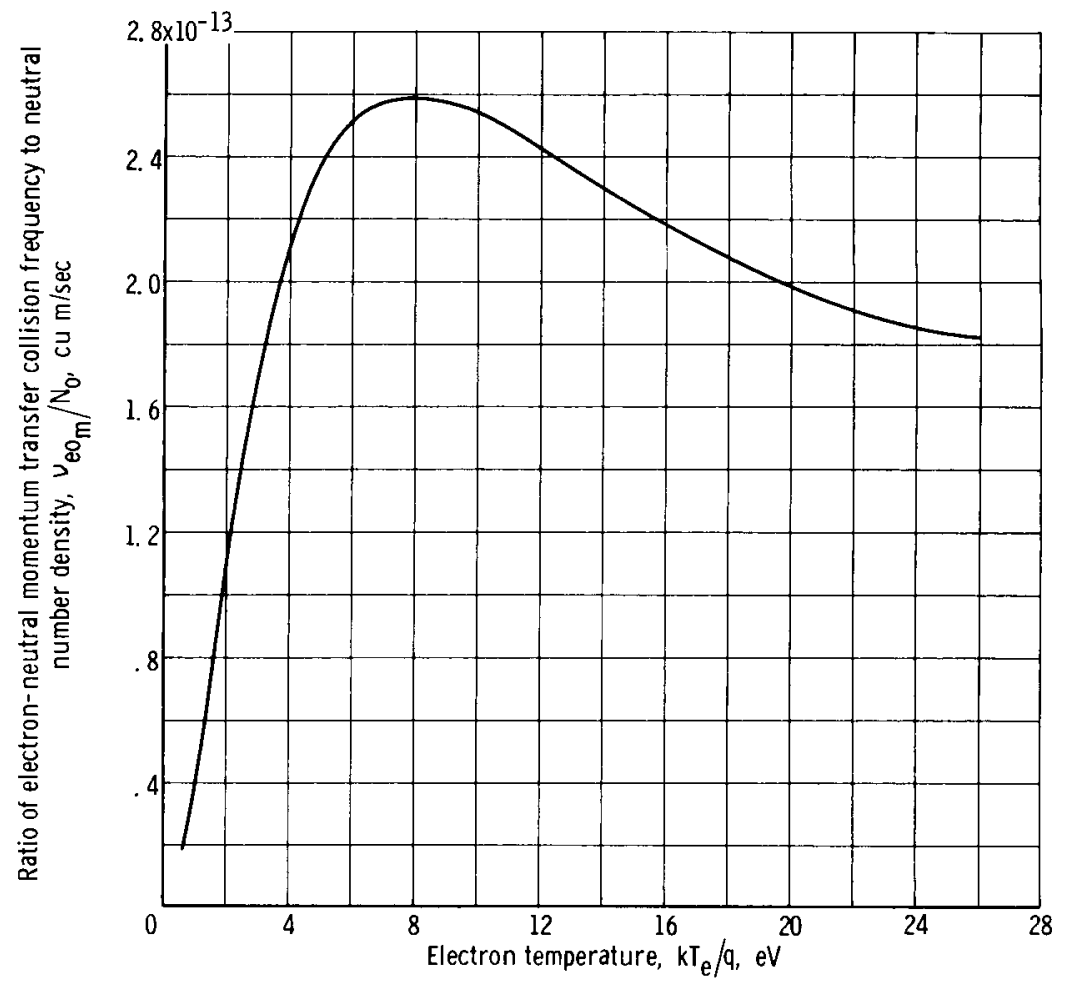

Figure 2. - Electron-neutral momentum transfer collision frequency for argon. 


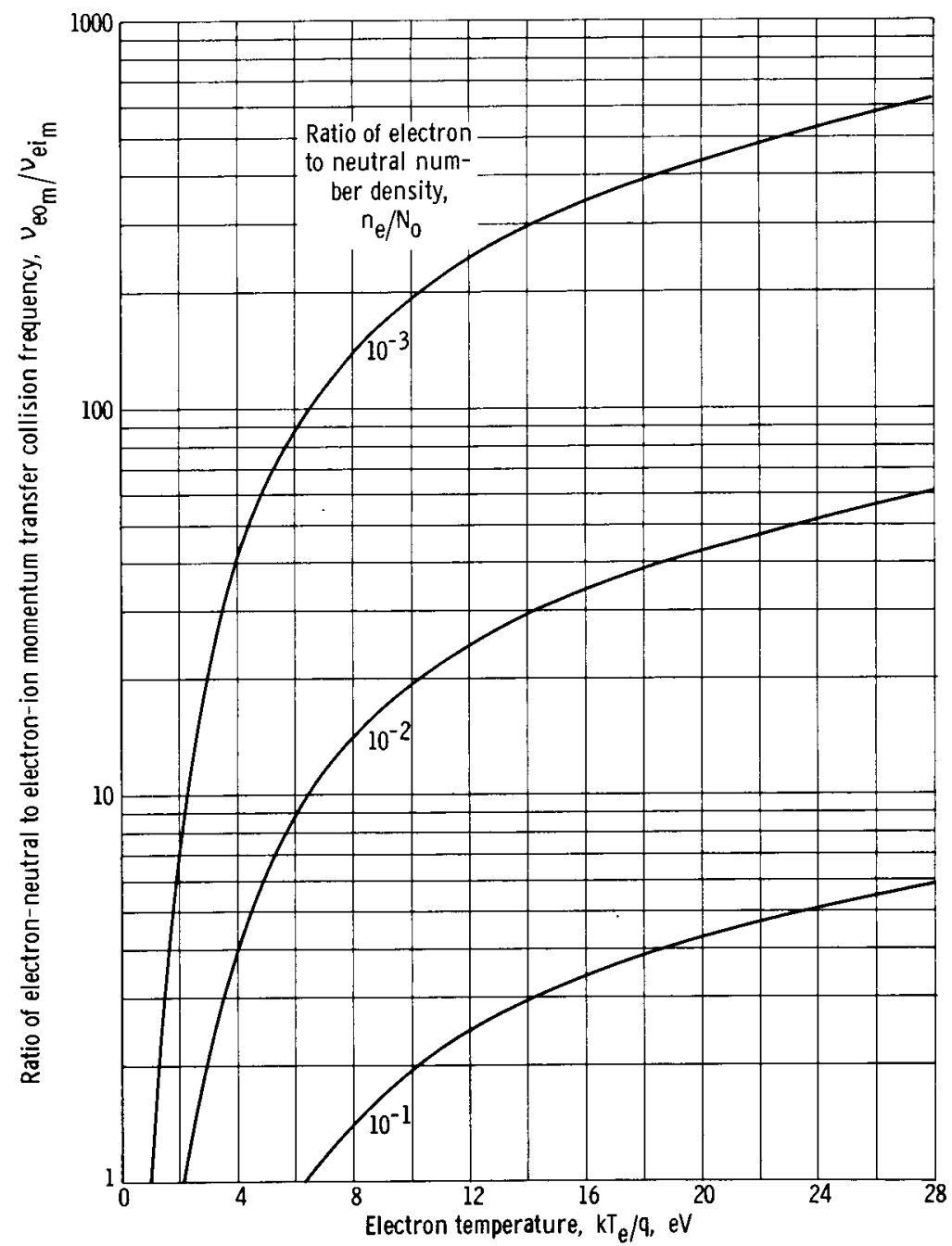

Figure 3. - Importance of electron-neutral collisions in argon.

The results of appendix B were used to calculate $\nu_{\mathrm{ei}} / \nu_{\mathrm{eo}}$ as a function of $\mathrm{n}_{\mathrm{e}} / \mathrm{n}_{\mathrm{o}}$ and $\mathrm{T}_{\mathrm{e}}$. Data from reference 7 (p. 31) for $\sigma_{\mathrm{m}}$ el were used to compute $\nu_{\mathrm{eo}}$ from equation (B17), and the results are presented in figure 2. The results of the calculation of $\nu_{\mathrm{ei}} / \nu_{\mathrm{eo}}$ are shown in figure 3. Since $\ln \Lambda$ appearing in equation (B18) varies very slowly with $\mathrm{n}_{\mathrm{e}}$ and $\mathrm{T}$, a constant value of 14 was used, which corresponds to $\mathrm{T}_{\mathrm{e}}=10^{5} \mathrm{o} \mathrm{K}$ and $\mathrm{n}_{\mathrm{e}}=10^{17}$ per cubic meter. For the Hall ion accelerator, the operating conditions are $\mathrm{T}_{\mathrm{e}} \gtrsim 10^{5} \mathrm{o} \mathrm{K}$ and $\mathrm{n}_{\mathrm{e}} / \mathrm{n}_{\mathrm{o}} \sim 10^{-2}$ to $10^{-3}$. As a result, it can be seen from figure 3 that electron-neutral collisions are much more important than electron-ion collisions. It therefore seems reasonable to neglect terms containing $\nu_{\mathrm{ei}} / \nu_{\mathrm{eo}}$ in equation (2). If this is done, equations (2b) and (2c) can be written as follows 


$$
\begin{gathered}
u_{e_{\theta}}\left(1+\frac{u_{e_{r}}}{\nu_{e_{m}} r}\right)=-u_{e_{z}} \frac{\omega_{e}}{\nu_{e o_{m}}}\left(1+\frac{1}{\omega_{e}} \frac{\partial u_{e_{\theta}}}{\partial z}\right) \\
u_{e_{z}}\left(1+\frac{1}{\nu_{e o}} \frac{\partial u_{\mathrm{m}}}{\partial z}\right)=u_{o_{z}}-\frac{q}{m_{e}{ }_{e o}} E_{z}+\frac{\omega_{e}}{\nu_{e o}} u_{e_{\theta}}-\frac{1}{m_{e^{n}} e^{\nu} o_{m}} \frac{\partial p_{e}}{\partial z}
\end{gathered}
$$

where $\omega_{\mathrm{e}}=\mathrm{Bq} / \mathrm{m}_{\mathrm{e}}$ is the electron cyclotron frequency. It will now be assumed that

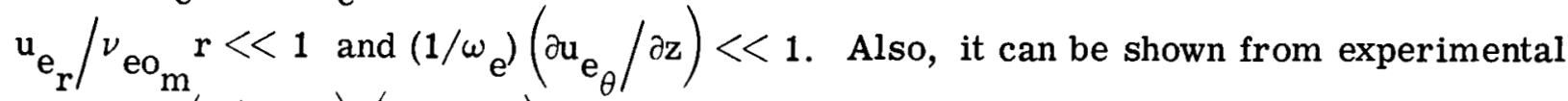
data that $\left(1 / v_{\mathrm{eo}_{\mathrm{m}}}\right)\left(\partial \mathrm{u}_{\mathrm{z}} / \partial z\right)<<1$. As a result, equations (3) and (4) become

$$
\begin{gathered}
\frac{u_{e_{\theta}}}{u_{e_{z}}}=-\frac{\omega_{e}}{\nu_{e o}} \\
u_{e_{z}}=u_{o_{z}}-\frac{q}{m_{e}{ }_{e o}} E_{z}+\frac{\omega_{e}}{\nu_{e o}} u_{e_{\theta}}-\frac{1}{m_{e} n_{e}{ }_{e o}} \frac{\partial p_{e}}{\partial z}
\end{gathered}
$$

Substituting equation (5) into equation (6) gives the following expressions for $u_{e_{\theta}}$ and $u_{e_{z}}:$

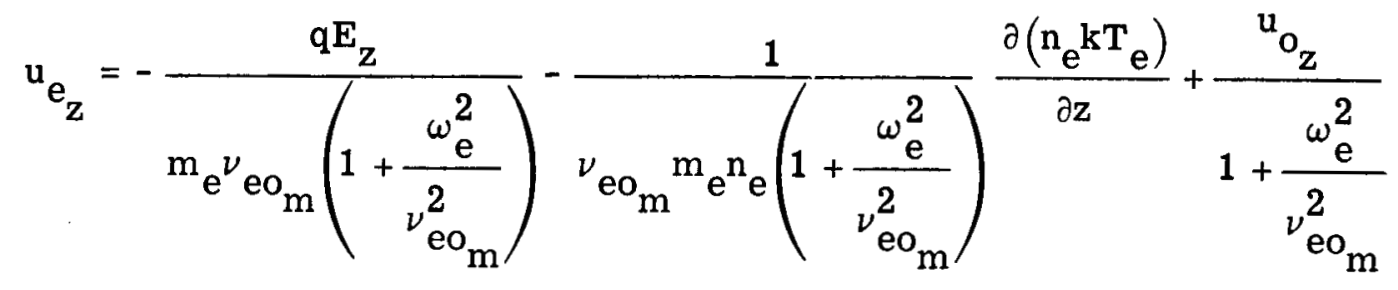

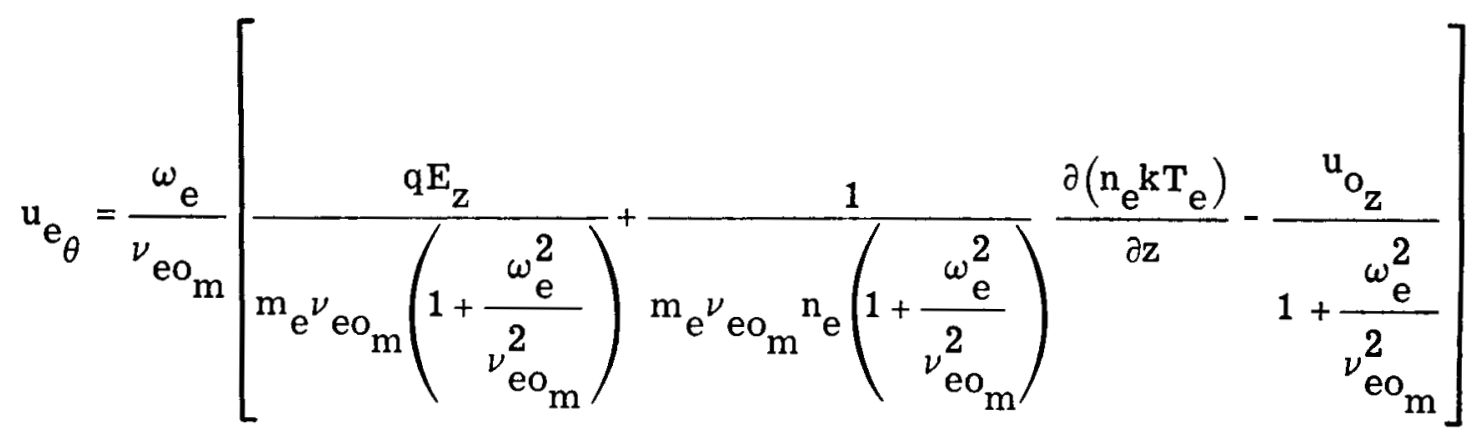


For a successful Hall accelerator, $\omega_{\mathrm{e}} / \nu_{\mathrm{eo}} \mathrm{m}_{\mathrm{m}}>1$. In this case $\left(\omega_{\mathrm{e}} / \nu_{\mathrm{eo}}\right)^{2}+1 \approx\left(\omega_{\mathrm{e}} / \nu_{\mathrm{eo}_{\mathrm{m}}}\right)^{2}$ in equations (7) and (8). Also, if $\left(\mathrm{u}_{\mathrm{o}_{\mathrm{z}}}\right) /\left[1+\left(\omega_{\mathrm{e}}^{2} / \nu_{\mathrm{eo}_{\mathrm{m}}}^{2}\right)\right]$ and the electron pressure gradient term $\partial \mathrm{n}_{\mathrm{e}} \mathrm{kT}_{\mathrm{e}} / \partial \mathrm{z}$ are neglected, equations (7) and (8) become:

$$
\begin{gathered}
u_{e_{z}}=-\frac{\mathrm{m}_{\mathrm{e}^{\nu} \mathrm{eo}_{\mathrm{m}}}}{\mathrm{qB}^{2}} \mathrm{E}_{\mathrm{z}}=-\left(\frac{{ }^{\mathrm{eo}_{\mathrm{m}}}}{\omega_{\mathrm{e}}}\right) \frac{\mathrm{E}_{\mathrm{z}}}{\mathrm{B}} \\
\mathrm{u}_{\mathrm{e}_{\theta}}=\frac{\mathrm{E}_{\mathrm{z}}}{\mathrm{B}}
\end{gathered}
$$

The azimuthal electron velocity given by equation (10) is just the $\overrightarrow{\mathrm{E}} \times \overrightarrow{\mathrm{B}} / \mathrm{B}^{2}$ drift velocity that the electrons would attain in a collisionless situation.

Under the same assumptions used to develop the electron equation of motion, the following electron energy equation can be obtained

$$
\begin{aligned}
& \nabla \cdot\left\{\vec{u}_{e}\left[m_{e} n_{e}\left(\frac{3}{2} \frac{p_{e}}{m_{e} n_{e}}+\frac{u_{e}^{2}}{2}\right)\right]\right\}+\vec{u}_{e} \cdot \nabla p_{e}+q n_{e} \vec{E} \cdot \vec{u}_{e}=n_{e}\left[\frac{3 m_{e} m_{i}}{\left(m_{e}+m_{i}\right)^{2}}\left(k T_{i}-k T_{e}\right) \nu_{e i}{ }_{m}\right. \\
& +\frac{3 \mathrm{~m}_{\mathrm{e}} \mathrm{m}_{\mathrm{o}}}{\left(\mathrm{m}_{\mathrm{e}}+\mathrm{m}_{\mathrm{o}}\right)^{2}}\left(\mathrm{kT}_{\mathrm{o}}-\mathrm{kT} \mathrm{e}^{2} \mathrm{eo}_{\mathrm{m}}-\frac{\mathrm{m}_{\mathrm{o}}}{\mathrm{m}_{\mathrm{o}}+\mathrm{m}_{\mathrm{e}}}\left(\mathrm{q} \varphi_{\mathrm{I}^{\nu} \mathrm{I}}+\sum \mathrm{q} \varphi \mathrm{ex}^{\nu} \mathrm{ex}\right)\right]
\end{aligned}
$$

where $\nu_{\mathrm{I}}$ and $\nu_{\mathrm{ex}}$ are the ionization and excitation collision frequencies, and $\varphi_{\mathrm{I}}$ and $\varphi_{\text {ex }}$ are the ionization and excitation potentials of the neutrals. The development of this expression is carried out in appendix $\mathrm{C}$ (eq. (C7)). For the experimental Hall accelerator, $\nu_{\mathrm{ei}}<<\nu_{\mathrm{eo}}$ and $\mathrm{T}_{\mathrm{e}} \gg>\mathrm{T}_{\mathrm{o}}$; therefore, the first term on the right side of equation (11) will be neglected, and $\mathrm{kT}_{\mathrm{o}}$ will be neglected compared with $\mathrm{kT}_{\mathrm{e}}$. Also, it will be assumed that the only important energy transfer term is $\vec{E} \cdot \vec{u}_{e}$ and that $\mathrm{E}_{\mathrm{r}} \mathrm{u}_{\mathrm{r}} \ll<\mathrm{E}_{\mathrm{z}} \mathrm{u}_{\mathrm{z}}$; therefore, equation (11) becomes

$$
\mathrm{qu}_{\mathrm{e}} \mathrm{E}_{\mathrm{z}}=-\frac{3}{2} \kappa \mathrm{eo}^{\nu} \mathrm{eo}_{\mathrm{m}} \mathrm{kT} \mathrm{e}
$$


where

$$
\kappa_{\mathrm{eo}}=\frac{2 \mathrm{~m}_{\mathrm{e}} \mathrm{m}_{\mathrm{o}}}{\left(\mathrm{m}_{\mathrm{e}}+\mathrm{m}_{\mathrm{o}}\right)^{2}}+\frac{\mathrm{m}_{\mathrm{o}}}{\frac{3}{2} \mathrm{kT}_{\mathrm{e}}{ }_{\mathrm{eo}}\left(\mathrm{m}_{\mathrm{o}}+\mathrm{m}_{\mathrm{e}}\right)}\left(\mathrm{q} \varphi_{\mathrm{I}^{\nu} \mathrm{I}}+\sum \mathrm{q} \varphi_{\mathrm{ex}}{ }_{\mathrm{ex}}\right) \approx \frac{2 \mathrm{~m}_{\mathrm{e}}}{\mathrm{m}_{\mathrm{o}}}+\frac{\mathrm{q} \varphi_{\mathrm{I}} \mathrm{I}+\sum \mathrm{q} \varphi_{\mathrm{ex}}{ }_{\mathrm{ex}}}{\frac{3}{2} \mathrm{kT}_{\mathrm{e}} \mathrm{eo}_{\mathrm{m}}}
$$

The quantity $\kappa_{\mathrm{eo}}$, which is a function of $\mathrm{T}_{\mathrm{e}}$, is the average energy lost by an electron in a collision with a neutral. Expressions are developed for $\nu_{I}$ and $\nu_{\text {ex }}$ in appendix C and are given by equations (C17) and (C18).

Solving equation (12) for $u_{e_{z}}$ results in

$$
\mathrm{u}_{\mathrm{z}}=-\frac{3}{2} \frac{{ }^{\kappa}{ }_{\mathrm{eo}}^{\nu} \mathrm{eo}_{\mathrm{m}}{ }^{\mathrm{kT}} \mathrm{e}}{\mathrm{qE}_{\mathrm{z}}}
$$

The expression that relates electron temperature, magnetic field, and electric field is obtained by combining equations (9) and (13):

$$
\left(\frac{E_{\mathrm{z}}}{\mathrm{B}}\right)^{2}=\frac{3}{2} \frac{\kappa_{\mathrm{eo}}}{\mathrm{m}_{\mathrm{e}}} \mathrm{kT}_{\mathrm{e}}
$$

The elastic energy loss term $2 \mathrm{~m}_{\mathrm{e}} / \mathrm{m}_{\mathrm{o}}$ in the parameter $\kappa_{\text {eo }}$ is much smaller than the ionization and excitation loss terms for the electron temperatures that exist in the argon Hall accelerator. Therefore, equation (14) can be written as

$$
\left(\frac{\mathrm{E}_{\mathrm{Z}}}{\mathrm{B}}\right)^{2}=\frac{\mathrm{q}}{\mathrm{m}_{\mathrm{e}}} \frac{1}{\nu_{\mathrm{eo}}}\left(\varphi_{\mathrm{I}}^{\nu_{\mathrm{I}}}+\sum \varphi_{\mathrm{ex}}{ }_{\mathrm{ex}}\right)
$$

Equation (15) was used to obtain an expression relating $E_{z}, B, N_{o}$, and $T_{e}$. By choosing a value of $\mathrm{T}_{\mathrm{e}}$ and $\mathrm{N}_{\mathrm{o}}$ and then determining $\nu_{\mathrm{I}}$ and $\nu_{\mathrm{ex}}$ (fig. 18, appendix C), $\mathrm{E}_{\mathrm{z}}$ can be determined as a function of $\mathrm{B}$. The electron temperature is determined by the ionization level necessary to maintain the discharge. It must be maintained at a level that gives a balance between the ionization rate and the loss rate of ions and electrons, including losses to the walls. Since the simplified analysis presented here does not include this wall transfer process, the electron temperature is an unknown parameter in determining $E_{z}$ as a function of $B$ from equation (15). 


\section{Anomalous Diffusion Analysis}

The electric field strengths predicted by the classical collision theory are much larger than those obtained experimentally. Therefore, an anomalous electron diffusion across the magnetic field as suggested by Janes and Dotson (ref. 8) and Brockman, Hess, and Weinstein (ref. 9) was considered. In the case of anomalous diffusion for $\left(\omega_{\mathrm{e}} / \nu_{\mathrm{eo}}\right)^{2} \gg 1$, the following expression for the electron velocity perpendicular to the magnetic field, neglecting the electron inertia terms, has been derived in reference 10 (eq. (33)):

$$
u_{e_{z}}=-\frac{\alpha}{B}\left[E_{z}+\frac{1}{q n_{e}} \frac{\partial\left(n_{e} k T_{e}\right)}{\partial z}\right]
$$

If the pressure gradient term is neglected, equation (16) becomes

$$
u_{e_{z}}=-\alpha \frac{E_{z}}{B}
$$

where $\alpha$ is a constant related to the mean-square deviation of the number density from the steady-state value of the number density (ref. 10). Comparison of the classical electron velocity equation (eq. (9)) with equation (17) shows that $\alpha$ plays the same role as the Hall parameter $\omega_{\mathrm{e}} / \nu_{\mathrm{eo}}$. As a result, $1 / \alpha$ might be called an effective Hall parameter.

The electron energy equation is given by equation (12). If the elastic energy transfer term $2 \mathrm{~m}_{\mathrm{e}} / \mathrm{m}_{\mathrm{o}}$ is neglected in the parameter $\kappa_{e o}$, the result for $\mathrm{u}_{\mathrm{e}_{\mathrm{z}}}$ is

$$
\mathrm{u}_{\mathrm{e}_{\mathrm{z}}}=-\frac{\varphi_{\mathrm{I}} \nu_{\mathrm{I}}+\sum \varphi_{\mathrm{ex}} \mathrm{ex}}{\mathbf{E}_{\mathrm{z}}}
$$

If equations (17) and (18) are combined, the following expression results:

$$
\frac{\mathrm{E}_{\mathrm{z}}^{2}}{\mathrm{~B}}=\frac{1}{\alpha}\left(\varphi_{\mathrm{I}} \nu_{\mathrm{I}}+\sum \varphi_{\mathrm{ex}}{ }_{\mathrm{ex}}\right)
$$

Comparing equation (19) with its classical counterpart (eq. (15)) shows again that $1 / \alpha$ appears in place of the Hall parameter. 


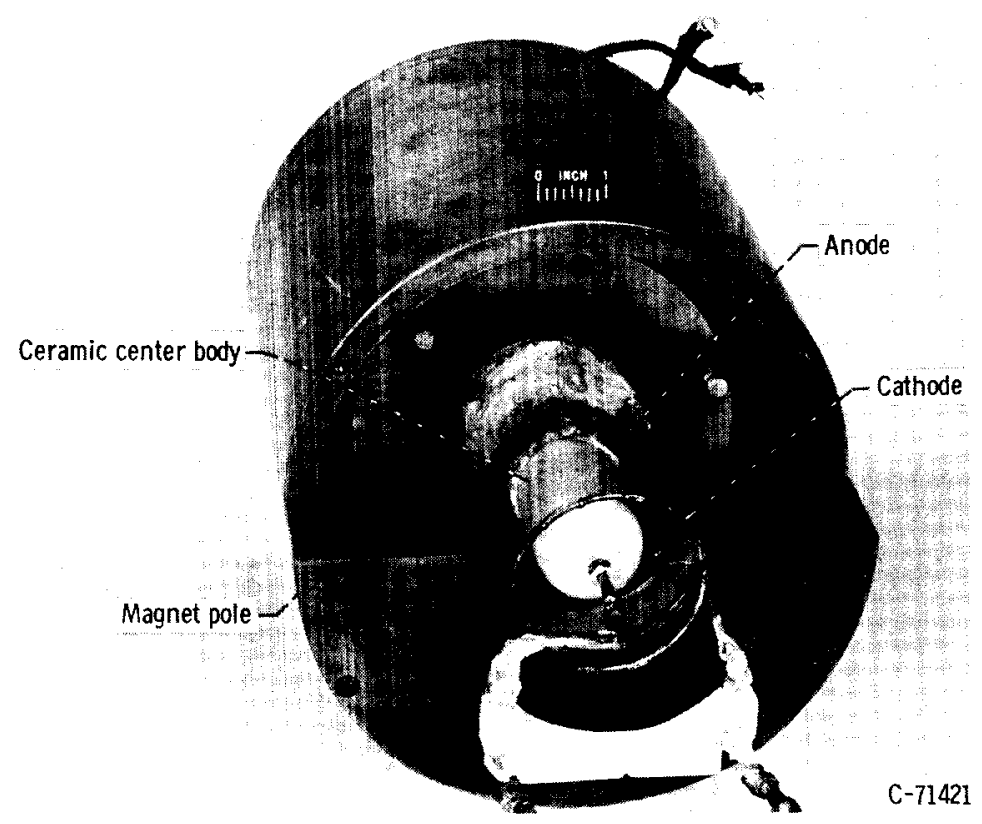

Figure 4. - Experimental Hall current ion accelerator.

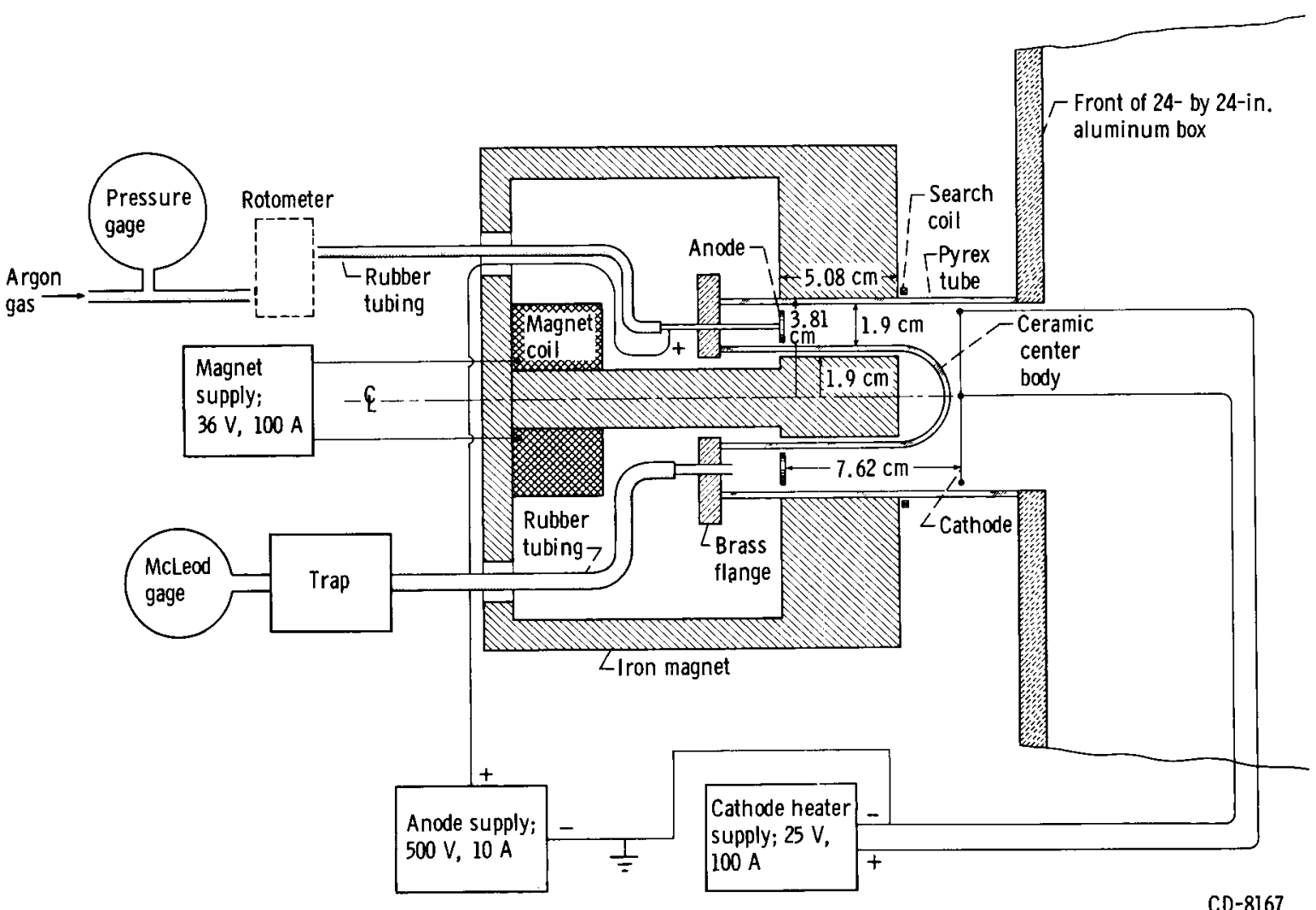

Figure 5. - Schematic diagram of experimental accelerator. 


\section{EXPERIMENT}

\section{Apparatus}

A photograph of the experimental accelerator is shown in figure 4 . Figure 5 is a schematic diagram of the accelerator and associated electrical equipment. The discharge was produced in an annular region formed by two concentric tubes. The outer tube was a 6-inch section of standard 3-inch diameter pyrex tube, and the inner tube was a 3. 8centimeter-diameter ceramic tube that fitted over the inner pole of the magnet. A brass flange and gasket provided a vacuum seal at the anode end of the accelerator, and at the cathode the 3-inch pyrex tube was connected to a 24-inch-square aluminum box connected by a 12-inch valve to the vacuum facility. This vacuum facility is a 15 -foot-long 5 -footdiameter stainless-steel tank equipped with four 32-inch diffusion pumps. Nominal pumping speed of the facility is $10^{5}$ liters per second.

Argon gas was introduced through four equally spaced holes in the annular stainlesssteel anode. Gas flow rate was monitored with a rotometer. The pressure of the discharge was measured at the anode by a McLeod gage. The gage was equipped with a liquid-nitrogen-cooled trap. An emitting cathode consisting of twelve 0.005-inch tantalum wires was used. The cathode (fig. 4) was constructed much like a bicycle wheel with the tantalum wires as the spokes, where the inner negative connection is the hub, and the outer positive ring is the rim. All power supplies were standard direct-current supplies, except the magnet supply, which had negligible ripple at full 100-ampere output.

Radial magnetic field strengths in the accelerator were calibrated as a function of current in the field coil. A profile of the radial field strength for a current of 9 amperes

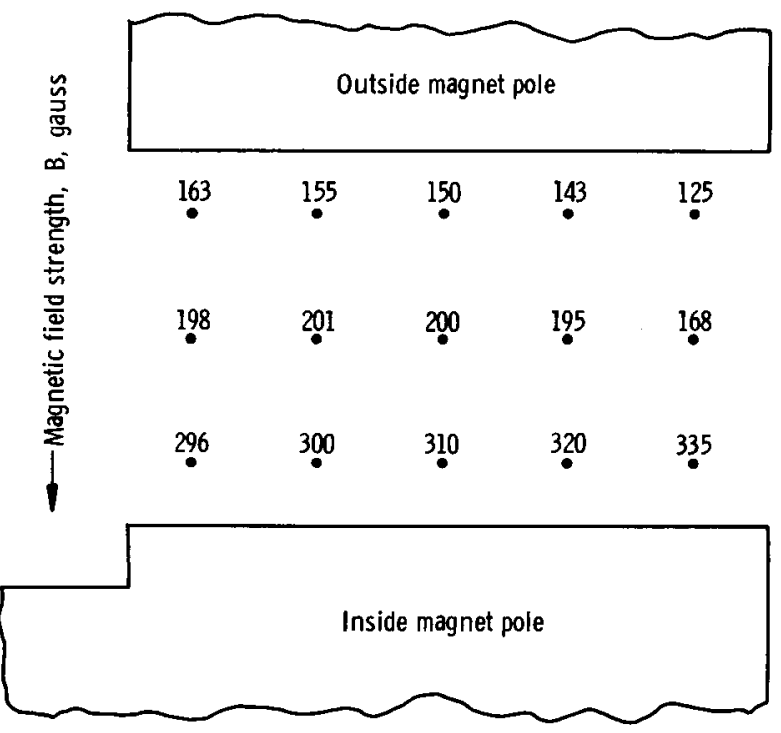

Figure 6. - Radial magnetic field strength profile. is shown in figure 6 . The value of the radial field in the middle of the accelerator (200 gauss) is the value quoted in presenting the experimental results. To avoid the hysteresis problem in calibrating the magnetic field, the iron magnet was first driven into the saturation region and then the calibration was made as the current was decreased from saturation. Therefore, to use the calibration curve, the magnet was first saturated and then the current reduced until the desired field was obtained. The maximum radial field that could be attained in the middle of the accelerator was $\mathbf{2 5 0}$ gauss. 


\section{Discharge Operation}

The discharge exhibits characteristics similar to those of the positive column of a glow discharge (ref. 11, p. 209); that is, an approximately constant electric field exists in the discharge, and the plasma is essentially neutral. The discharge was initiated in the pressure range of $10^{-3}$ millimeter of mercury by raising the anode potential to between 200 and 300 volts and then switching the magnetic field on and off. Once the discharge was established, the anode potential and magnetic field were adjusted to the desired conditions. Before collecting data, the discharge was allowed to reach steady-state operation. All the data reported here were obtained at a constant total current of 1 ampere. If it is assumed that the current is uniform across the accelerator, $\mathrm{I}_{\mathrm{T}}$ of 1 ampere corresponds to the total current density $\mathrm{J}_{\mathrm{T}}$ of 289 amperes per square meter. All potentials reported were measured with respect to ground.

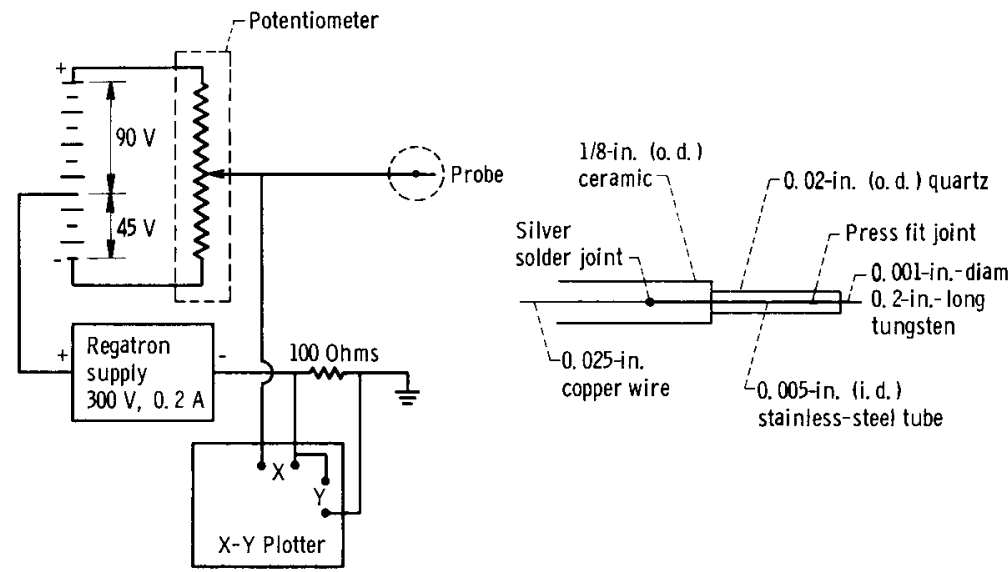

(a) Langmuir probe and circuit.
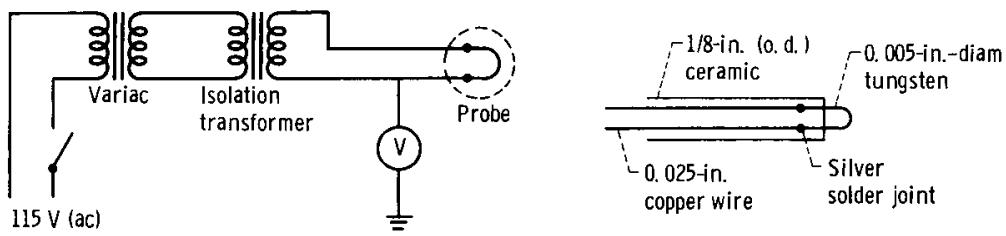

(b) Emitting probe and circuit.
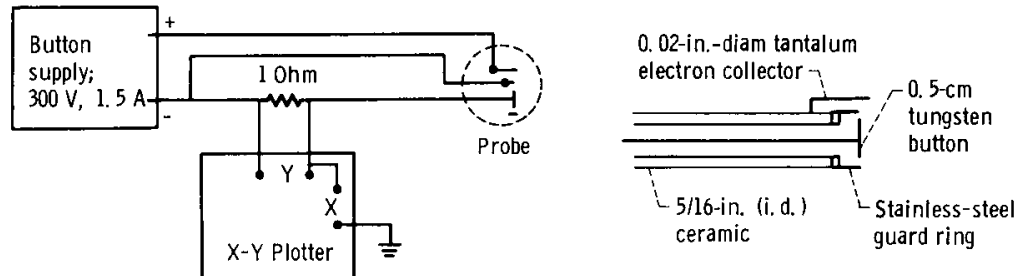

(c) Button probe and circuit.

Figure 7. - Diagnostic probes. 
- Operation of the discharge is strongly dependent on the cathode temperature, indicating that the emitted cathode current is emission limited rather than space-charge limited. By raising the cathode temperature, the total current increased while the anode potential decreased. In obtaining the data presented here, the cathode temperature was maintained at a constant value throughout the interval when data were being recorded.

\section{DIAGNOSTIC METHODS AND EQUIPMENT}

\section{Langmuir and Emitting Probes}

Measurements of electron temperature, electron number density, and plasma potential were made with a 0.001 -inch-diameter cylindrical tungsten Langmuir probe and a 0.005-inch-diameter tungsten emitting probe. Both probes are illustrated in figure 7. Operation of an emitting probe is described in reference 12. As the probe is heated, the floating potential rises to a plateau. At this point, the emission current from the probe equals the random electron current arriving at the probe. As a result, the floating potential of the probe closely approximates the plasma potential. The emitting probe was used only in obtaining the plasma potential.

It was assumed that the magnetic field did not affect the Langmuir probe operation. This appears to be a reasonable assumption since the measured Hall current through the

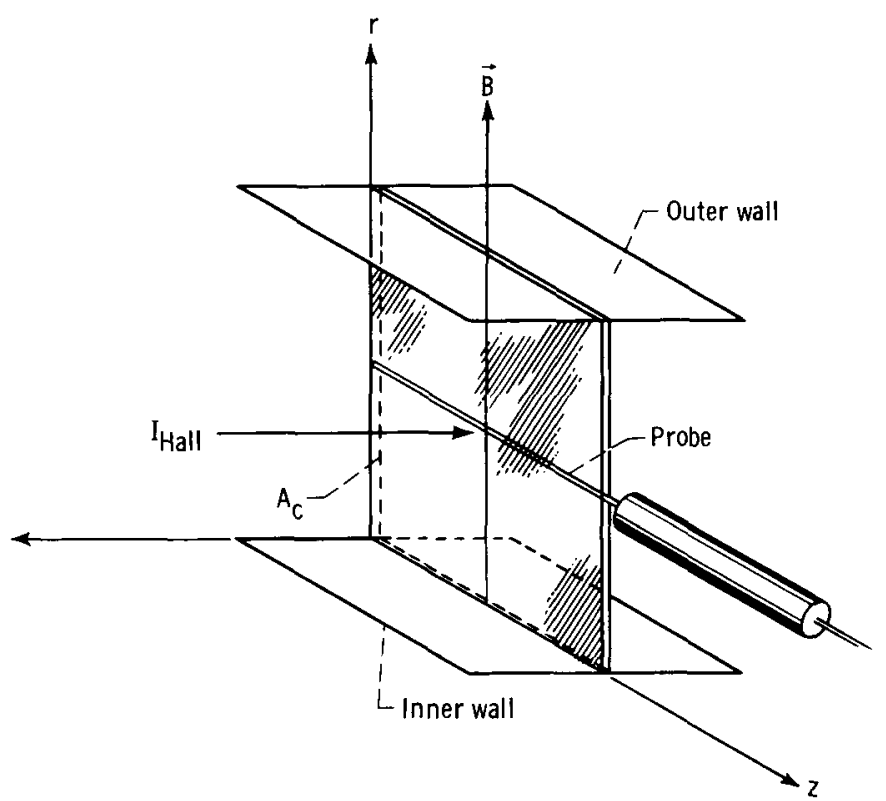

CD-8168

Figure 8. - Probe current collecting volume. radial cross section $A_{c}$ of the volume, from which the probe could easily draw current, was large compared with the measured saturation electron current (fig. 8).

The Langmuir probe data were reduced by two different methods: first, the relation between the electron current and the electron distribution function derived by Druyvesteyn (ref. 13), and second, a method described subsequently as "corrected Maxwellian." In determining the electron number density $\mathrm{n}_{\mathrm{e}}$ by either method, the plasma potential used in the calculation was obtained with the emitting probe.

Associated with the anomalous electron diffusion across the magnetic 


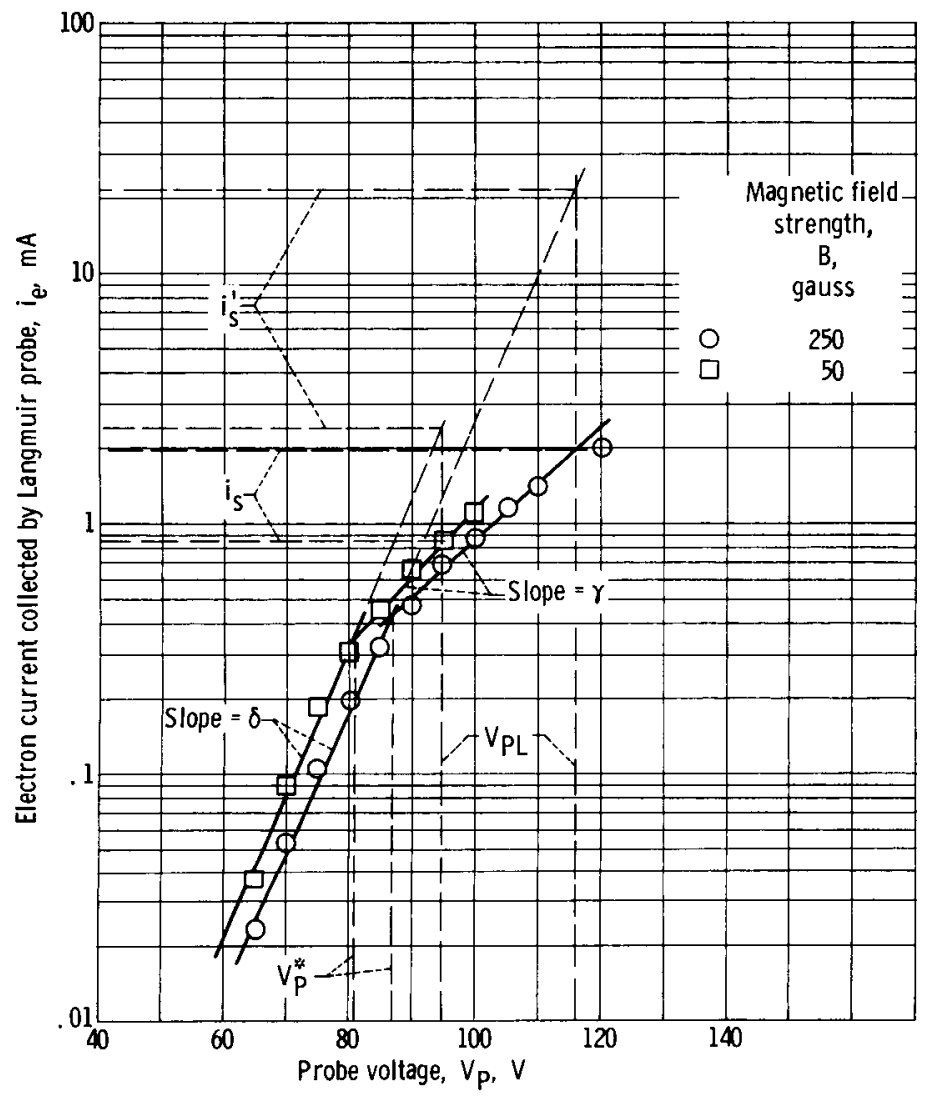

Figure 9. - Typical Langmuir probe data.

field are large oscillations in the plasma potential. For low magnetic fields ( $\mathrm{B}<50$ gauss), the oscillations are small. As pointed out in reference 14 , oscillations near the plasma potential will cause a reduction in the electron saturation current measured by a Langmuir probe. In figure 9, typical Langmuir probe curves are plotted for magnetic fields of 50 and 250 gauss. The plasma potentials $\mathrm{V}_{\mathrm{PL}}$ shown in figure 9 were determined by the emitting probe. If the electron distribution function is Maxwellian, the probe curve should increase linearly to $V_{\mathrm{PL}}$ and then level off (ref. 15). As shown in figure 9, however, the probe curve has a break at a lower value $\mathrm{V}_{\mathrm{P}}^{*}$, rather than $\mathrm{V}_{\mathrm{PL}}$. This result can be interpreted in two ways. The most obvious conclusion is that the distribution function is not Maxwellian. Secondly, it could be concluded that the oscillations in the plasma potential cause a premature break in the probe curve, but that the distribution function is still Maxwellian. In this case, the true electron saturation current can be taken as $i_{S}^{\prime}$ (fig. 9). If the probe curve is interpreted in this manner, the electron number density and temperature can be determined as usual (ref. 15). The probe data reduced this way is referred to in the figures as corrected Maxwellian.

If the effect of the plasma oscillations is ignored, the data can be reduced by the Druyvesteyn method in the following manner. If an isotropic distribution function is assumed to exist for the electrons, the second derivative of the curve for electron current against probe voltage will be proportional to the electron distribution function (ref. 13)

$$
\mathrm{n}_{\mathrm{e}^{\varphi(\mathrm{U})}}=\frac{2}{\mathrm{Aq}}\left(\frac{2 \mathrm{~m}_{\mathrm{e}} \mathrm{U}}{\mathrm{q}}\right)^{1 / 2} \frac{\mathrm{d}^{2} \dot{\mathrm{i}}_{\mathrm{e}}}{\mathrm{dV}_{\mathrm{P}}^{2}}
$$

where $U=V_{P L}-V_{P}$ is the difference between the plasma potential and the probe potential, $A$ is the probe surface area, $d^{2} i_{e} / d V_{P}^{2}$ is the second derivative of the electron 
- current collected by the probe, and $\mathrm{n}_{\mathrm{e}} \varphi(\mathrm{U})$ is the electron density within the energy in- crement dU.

By definition, the electron number density is

$$
\mathrm{n}_{\mathrm{e}}=\int_{0}^{\infty} \mathrm{n}_{\mathrm{e}} \varphi(\mathrm{U}) \mathrm{dU}
$$

Substituting equation (20) into equation (21) and integrating by parts yield

$$
n_{e}=\frac{2}{A q}\left(\frac{2 m_{e}}{q}\right)^{1 / 2}\left[\left(U^{1 / 2} \frac{d i_{e}}{d U}\right)_{0}^{\infty}-\frac{1}{2} \int_{0}^{\infty} U^{-1 / 2}\left(\frac{d i_{e}}{d U}\right) d U\right]
$$

and the first term in the parentheses vanishes because $\left(\mathrm{di}_{\mathrm{e}} / \mathrm{dU}\right)_{\mathrm{U}=\infty}=0$. Therefore, the electron number density is

$$
n_{e}=\frac{-1}{A q}\left(\frac{2 m_{e}}{q}\right)^{1 / 2} \int_{0}^{\infty} U^{-1 / 2}\left(\frac{d i}{d U}\right) d U
$$

The electron current $i_{e}$ was taken as $\left(i_{p}-i_{i}\right)$, where $i_{p}$ is the measured probe current and $i_{i}$ was estimated graphically by drawing a straight line through the point determined by zero current and plasma potential and tangent to the ion saturation portion of the probe trace. To reduce this equation (23) further, a relation must be obtained between $i_{e}$ and U. For all experimental probe traces that were recorded in cases where $B>0$, this relation could be well represented by two exponential curves. (Fig. 9 is a typical plot of the logarithm $i_{e}$ against the probe potential.) Therefore, the electron current to the probe can be approximated as follows

$$
\left.\begin{array}{ll}
i_{e}=i_{s} e^{-\gamma U} & 0 \leq U \leq U^{*} \\
i_{e}=i_{S}^{\prime} e^{-\delta U} & U^{*} \leq U<\infty
\end{array}\right\}
$$

where $\mathrm{U}^{*}=\mathrm{V}_{\mathrm{PL}}-\mathrm{V}_{\mathrm{P}}^{*}, \delta$ and $\gamma$ are the slopes of the two straight-line approximations to $\log i_{e}, i_{S}$ is taken as the electron current at the plasma potential $v_{P L}$, and $i_{S}^{q}$ is the electron saturation current obtained by extrapolating the first part of the probe trace to the plasma potential $V_{\mathrm{PL}}$. When $\mathrm{B} \approx 0$, the plasma potential determined by the break 
in the probe trace is slightly higher than the plasma potential measured with the emitting probe. Using the plasma potential determined by the emitting probe for cases where $B \neq 0$ would ther efore appear to be a conservative estimate.

Using equation (24) in the number density expression (eq. (23)) results in

$$
\mathrm{n}_{\mathrm{e}}=\frac{1}{\mathrm{Aq}}\left(\frac{2 \mathrm{~m} \mathrm{e}}{\mathrm{q}}\right)^{1 / 2}\left(\mathrm{i}_{\mathrm{s}} \gamma^{1 / 2} \int_{0}^{\gamma \mathrm{U}^{*}} \mathrm{x}^{-1 / 2} \mathrm{e}^{-\mathrm{x}} \mathrm{dx}+\mathrm{i}_{\mathrm{s}}^{\prime} \delta{ }^{1 / 2} \int_{\delta \mathrm{U}^{*}}^{\infty} \mathrm{x}^{-1 / 2} \mathrm{e}^{-\mathrm{x}} \mathrm{dx}\right)
$$

where the integrals are incomplete gamma functions (tabulated in ref. 16, p. 978).

The mean random electron energy, or electron temperature, can also be determined from the probe trace, since by definition

$$
\frac{3}{2}\left(\frac{\mathrm{kT}_{\mathrm{e}}}{\mathrm{q}}\right)_{\exp }=\frac{1}{\mathrm{n}_{\mathrm{e}}} \int_{0}^{\infty} \mathrm{n}_{\mathrm{e}} \varphi(\mathrm{U}) \mathrm{U} \mathrm{dU}
$$

where $\left(\mathrm{kT}_{\mathrm{e}} / \mathrm{q}\right)_{\exp }$ is the experimentally determined electron temperature. This temperature is not necessarily equivalent to the electron temperature used in the theory, since in deriving the expressions for $v_{\mathrm{eo}}, \nu_{\mathrm{I}}$, and $v_{\mathrm{ex}}$ it was assumed that the distribution function was Maxwellian.

Substituting equation (20) into (26) and integrating by parts give

$$
\frac{3}{2}\left(\frac{k T_{e}}{q}\right)_{\exp }=-\frac{3}{\operatorname{Aqn}_{e}}\left(\frac{2 m_{e}}{q}\right)^{1 / 2} \int_{0}^{\infty} U^{1 / 2}\left(\frac{d_{e}}{d U}\right) d U
$$

where the condition ( $\left.\mathrm{di}_{\mathrm{e}} / \mathrm{dU}\right)_{U=\infty}=0$ has been used. Finally, use of equation (24) in equation (27) yields

$$
\frac{3}{2}\left(\frac{k T_{e}}{q}\right)_{\exp }=\frac{3}{q A n_{e}}\left(\frac{2 m_{e}}{q}\right)^{1 / 2}\left(i_{s} \gamma^{-1 / 2} \int_{0}^{\gamma U^{*}} x^{1 / 2} e^{-x} d x+i_{s}^{\prime} \delta^{-1 / 2} \int_{\delta U^{*}}^{\infty} x^{1 / 2} e^{-x} d x\right)
$$

where the integrals are the same as in equation (25). 


\section{Hall Current Measurement}

As a check on the methods described for measuring the electron number density, a method based on knowing the electron Hall current in the accelerator was also used. The azimuthal Hall current was measured in a way similar to that used in reference 9 . When the discharge is turned off, the collapsing azimuthal Hall current induces a voltage in a coil wrapped around the outer pyrex tube. To pick up this induced voltage, a 1000-turn search coil was wrapped around the pyrex tube just downstream of the outer pole of the magnet. The coil was located at an axial station, $z=5.08$ centimeters (fig. 5). The signal from the coil was fed into an integrating circuit, and the result was displayed on an oscilloscope. The search coil was calibrated by simulating the Hall current with a coil placed between the poles of the accelerator magnet. By switching off a known current in the calibration coil, the recorded oscilloscope reading was plotted as a function of the simulated Hall current. The steady magnetic field produced by the iron magnet of the accelerator had a negligible effect on the calibration. The effect of a nonuniform Hall current was simulated by moving the calibration coil. By placing this coil at several axial positions between the magnet poles with the same value of current and comparing the oscilloscope readings, the effect of nonuniformities in the azimuthal Hall current could be determined. A maximum change of 20 percent from the reading when the calibration coil was centered under the magnet poles resulted when the coil was moved to a position with one edge at the cathode position. This would simulate the extreme case of having most of the Hall current occurring between the cathode and the downstream edge of the magnet.

The measured electron Hall currents were used to obtain a mean number density in the following manner. From equation (10), which neglects the electron pressure gradient and assumes $\left(\omega_{\mathrm{e}} / \nu_{\mathrm{eo}}\right)^{2}>1$,

$$
\left|\mathrm{J}_{\text {Hall }}\right|=\left|\mathrm{J}_{\mathrm{e}_{\theta}}\right|=\mathrm{qnu}_{\mathrm{e}_{\theta}} \approx \frac{\mathrm{qnE} \mathrm{z}}{\mathrm{B}}
$$

Therefore, the mean number density can be obtained from measured mean values of $\mathrm{J}_{\mathrm{Hall}}, \mathrm{E}_{\mathrm{z}}$, and $\mathrm{B}$ :

$$
\overline{\mathrm{n}} \approx \frac{\left|\overline{\mathrm{J}}_{\text {Hall }}\right|}{\frac{\mathrm{q} \overline{\mathrm{E}}_{\mathrm{z}}}{\overline{\mathrm{B}}}}
$$

To convert the measured Hall current into a current density, it was divided by the area bounded by the inner and outer tubes, the anode, and the downstream edge of the magnet. 
This area equals 9.67 square centimeters.

If the electron Hall current density and the axial electron current density are known, the mean effective Hall parameter $\overline{\omega_{\mathrm{e}} \mathrm{e}_{\mathrm{e}}}$ can be computed. The following expression is obtained from equation (5):

$$
\frac{\left|\overline{\mathrm{J}}_{\mathrm{e}_{\theta}}\right|}{\left|\overline{\mathrm{J}}_{\mathrm{e}_{\mathrm{z}} \mid}\right|}=\left|\frac{\overline{\mathrm{u}}_{\mathrm{e}_{\theta}}}{\overline{\mathrm{u}}_{\mathrm{e}_{\mathrm{z}}}}\right|=\overline{\omega_{\mathrm{e}^{\tau} \mathrm{e}}}
$$

\section{Button Probe}

Axial electron current densities were determined by measuring the axial ion current density and then subtracting this result from the total current density. The ion current density was measured with a 0.5 -centimeter-diameter guard-ringed tungsten button probe shown in figure 7 (c) (p. 12). Biasing the button negative with respect to the plasma potential results in ions being collected by the button, while electrons are repelled. To complete the electrical circuit, an electron collector is placed near the button. As the button becomes more and more negative, eventually all the electrons will be repelled, and only ions will be collected. There will be some value of the probe potential beyond which no further ion current will be collected by the button. The value of the current at this point is an upper bound on the axial ion current moving through the plasma. In operating the probe, both the button and the button guard ring were maintained at the same potential. When this was done, the probe current saturated, indicating that any additional ion current attracted by the sheath growth was collected by the guard ring.

\section{Neutral Number Density Measurement}

The McLeod gage pressure measurements were used to establish the neutral number density. The neutral atoms are essentially in free molecular flow throughout the discharge; examination of similar cold flows indicates a small (30 percent) pressure drop through the accelerator. This coupled with the knowledge that the discharge is only slightly ionized indicates that the neutral density is approximately constant. Since the mean free paths of the particles in the accelerator are larger than the characteristic length of the apparatus, the condition of equal pressures in the accelerator and McLeod gage cannot be used in determining the neutral density; however, conservation of mass must exist. If it is assumed that the electrons and ions have completely recombined in passing through the tube connecting the accelerator and the McLeod gage, the conservation of mass can be expressed as follows 


$$
\rho_{\mathrm{o}}^{\prime} \overline{\mathrm{v}}_{\mathrm{o}}^{\prime}=\rho_{\mathrm{e}} \overline{\mathrm{v}}_{\mathrm{e}}+\rho_{\mathrm{i}} \overline{\mathrm{v}}_{\mathrm{i}}+\rho_{\mathrm{o}} \overline{\mathrm{v}}_{\mathrm{o}}
$$

where the primed quantities indicate conditions in the McLeod gage and the unprimed quantities indicate conditions in the accelerator and $\rho_{\mathrm{e}}=\mathrm{n}_{\mathrm{e}} \mathrm{m}_{\mathrm{e}}, \rho_{\mathrm{i}}=\mathrm{n}_{\mathrm{i}} \mathrm{m}_{\mathrm{i}}, \rho_{\mathrm{o}}=\mathrm{N}_{\mathrm{o}} \mathrm{m}_{\mathrm{o}}$. If equal ion and electron densities and $m_{0} \approx m_{i}$ are assumed, the neutral number density is obtained from equation (29)

$$
\mathrm{N}_{\mathrm{o}}=\frac{\mathrm{N}_{\mathrm{o}}^{\mathrm{i}} \overline{\mathrm{v}}_{\mathrm{o}}^{\prime}-\mathrm{n}\left(\overline{\mathrm{v}}_{\mathrm{i}}+\frac{\mathrm{m}_{\mathrm{e}}}{\mathrm{m}_{\mathrm{o}}} \overline{\mathrm{v}}_{\mathrm{e}}\right)}{\overline{\mathrm{v}}_{\mathrm{o}}}
$$

For free molecular flow, $\bar{v}=\sqrt{8 \mathrm{kT} / \pi \mathrm{m}}$. This free molecular flow speed was used for $\bar{v}_{o}^{t}$ and $\bar{v}_{o}$ in equation (30). For $\bar{v}_{i}$ the ion velocity required for a stable sheath, given by the expression $\bar{v}_{i}=\sqrt{\mathrm{kT}_{\mathrm{e}} / \mathrm{m}_{\mathrm{o}}}$ (ref. 17), was used. Since current conservation requires equal arrival rates for electrons and ions $\left(n \bar{v}_{i}=n \bar{v}_{e}\right)$ and $m_{e}$ is neglected compared with $m_{0}$, equation (30) becomes

$$
\mathrm{N}_{\mathrm{O}}=\frac{\mathrm{N}_{\mathrm{O}}^{\prime}-\mathrm{n} \sqrt{\frac{\pi \mathrm{T}_{\mathrm{e}}}{8 \mathrm{~T}_{\mathrm{o}}^{\prime}}}}{\sqrt{\frac{\mathrm{T}_{\mathrm{o}}}{\mathrm{T}_{\mathrm{o}}^{\prime}}}}
$$

Typically, $\mathrm{N}_{\mathrm{o}}^{\mathrm{q}} \sim 10^{20}$ per cubic meter and $\mathrm{n} \sqrt{\pi \mathrm{T}_{\mathrm{e}} / 8 \mathrm{~T}_{\mathrm{o}}^{\mathrm{i}}} \sim 10^{18}$ per cubic meter; therefore, the second term in the numerator of equation (32) can be neglected, and the neutral density in terms of the measured McLeod pressure becomes

$$
N_{o}=N_{o}^{2} \sqrt{\frac{T_{o}^{\prime}}{T_{o}}}=\frac{p_{o}^{\prime}}{k \sqrt{T_{o}^{\prime} T_{o}}}
$$

Before $N_{0}$ can be computed, the temperatures $T_{0}$ and $T_{o}^{\prime}$ must be known. The temperature in the McLeod gage should be nearly room temperature; therefore, a value of $300^{\circ} \mathrm{K}$ was used for $\mathrm{T}_{\mathrm{o}}^{\prime}$. The neutral temperature in the discharge $\mathrm{T}_{\mathrm{o}}$ is not known, but in order to compute $\mathrm{N}_{0}$, a value of $500^{\circ} \mathrm{K}$ was chosen for $\mathrm{T}_{\mathrm{O}^{\circ}}$. This value of $500^{\circ} \mathrm{K}$ should be higher than what actually exists, therefore, the computed neutral number densities might be slightly low. 


\section{RESULTS AND DISCUSSION}

\section{Electron Distribution Function}

If a Maxwellian distribution exists for the electrons and no plasma oscillations are present, the Langmuir probe curve, $\log \mathrm{i}_{\mathrm{e}}$ against $\mathrm{V}_{\mathrm{p}}$, would lie on a straight line for $\mathrm{V}_{\mathrm{P}} \leq \mathrm{V}_{\mathrm{PL}}$. As shown in figure 9 (p. 14), however, $\log \mathrm{i}_{\mathrm{e}}$ is not a single linear function, but can be closely approximated by two linear functions. It might therefore be concluded either that the electron distribution function is not Maxwellian for $B>0$ or that plasma oscillations exist. More likely, a combination of these two conditions exists. In other words, the distribution function is not Maxwellian, and the probe curve exhibits a reduced electron saturation current ( $i_{s}$ in fig. 9) due to plasma oscillations.

Since a Maxwellian distribution was assumed in deriving the expressions for ${ }^{\mathrm{eo}} \mathrm{m}$, $\nu_{I}$, and $\nu_{\text {ex }}$, the theoretical analysis of the accelerator will be in error. The high-energy tail of the distribution is the region where the largest departures from a Maxwellian are likely to exist. As a result, the ionization and excitation collision frequencies, which depend primarily on the high-energy tail of the distribution, will show the greatest error because a Maxwellian distribution was assumed. If the high-energy tail of the distribution function is below that of a Maxwellian distribution, the values of $\nu_{\text {ex }}$ and $\nu_{\mathrm{I}}$ based on a

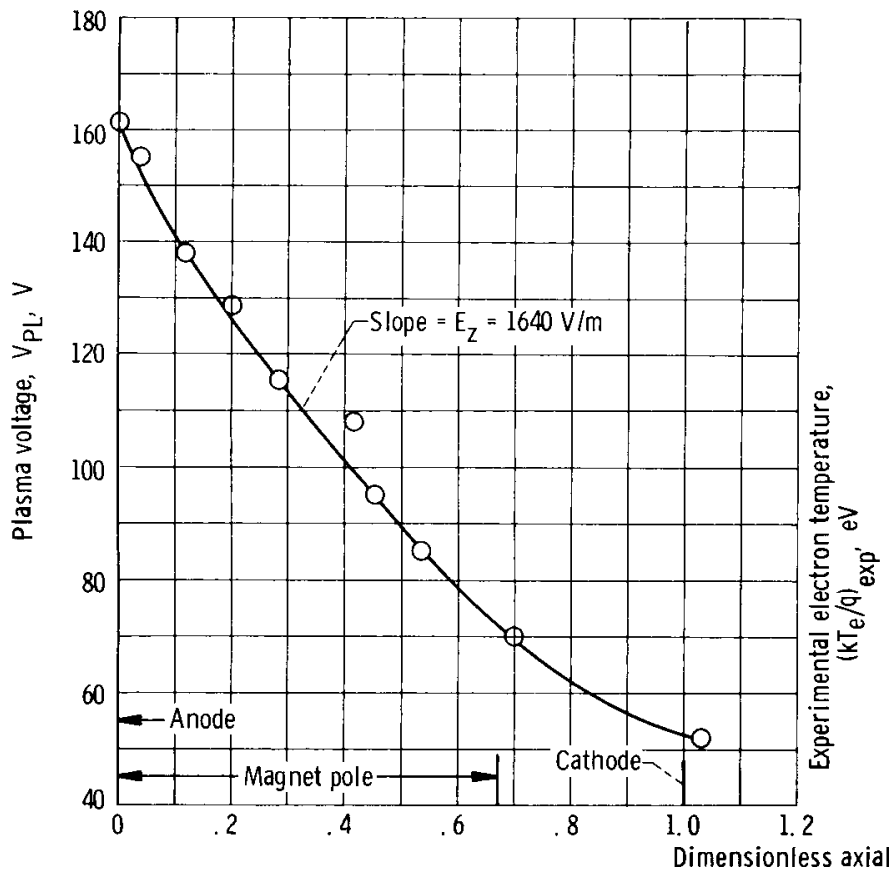

(a) Plasma potential.

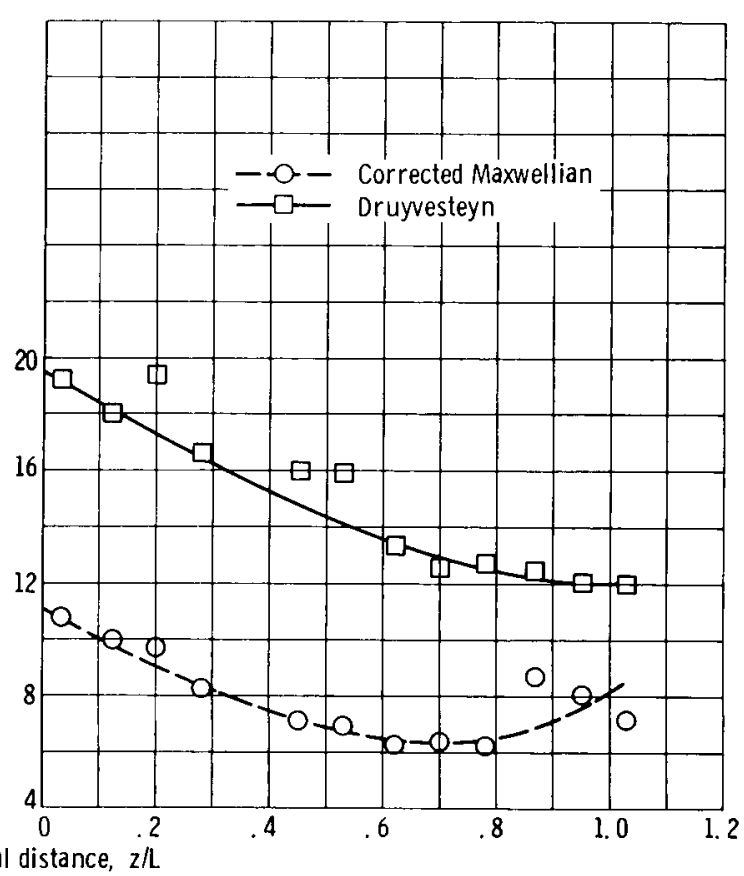

(b) Electron temperature.

Figure 10. - Variation of plasma properties through accelerator. Total applied voltage, 162 volts; total current density, 289 amperes per square meter; magnetic field strength, 200 gauss; neutral number density, $5.2 \times 10^{19}$ per cubic meter; mass flow rate, $10^{-3}$ gram per second; accelerator length, 7.62 centimeters. 
Maxwellian distribution will be larger than the values obtained for $\nu_{\text {ex }}$ and $\nu_{I}$ with the - correct distribution function.

\section{Experimental Variation of Plasma Properties Through Accelerator}

In figure 10 the experimentally determined variations of plasma potential, electron temperature, number density, ion current density, and axial ion velocity through the accelerator are presented. The electron number density and temperature were determined by both the Druyvesteyn and corrected Maxwellian methods. It can be seen from figure 10(a) that the plasma potential varies almost linearly with axial position through much of the accelerator and as a result, $\mathrm{E}_{z}$ is approximately a constant. A 50- to 60-volt sheath was observed to exist at the cathode for all magnetic fields investigated.

As shown in figure $10(\mathrm{~b})$ the electron temperature is a generally increasing function in moving from the cathode to the anode. The corrected Maxwellian electron temperatures are lower than those determined by the Druyvesteyn method. For $z / L>0.7$ the magnetic field is small since these stations are outside the magnet poles, and the Druyvesteyn data and corrected Maxwellian data tend to approach agreement.

Figure 10(c) shows that the electron number density increases rapidly through the first one-third of the accelerator and then decreases up to the cathode. The initial in-

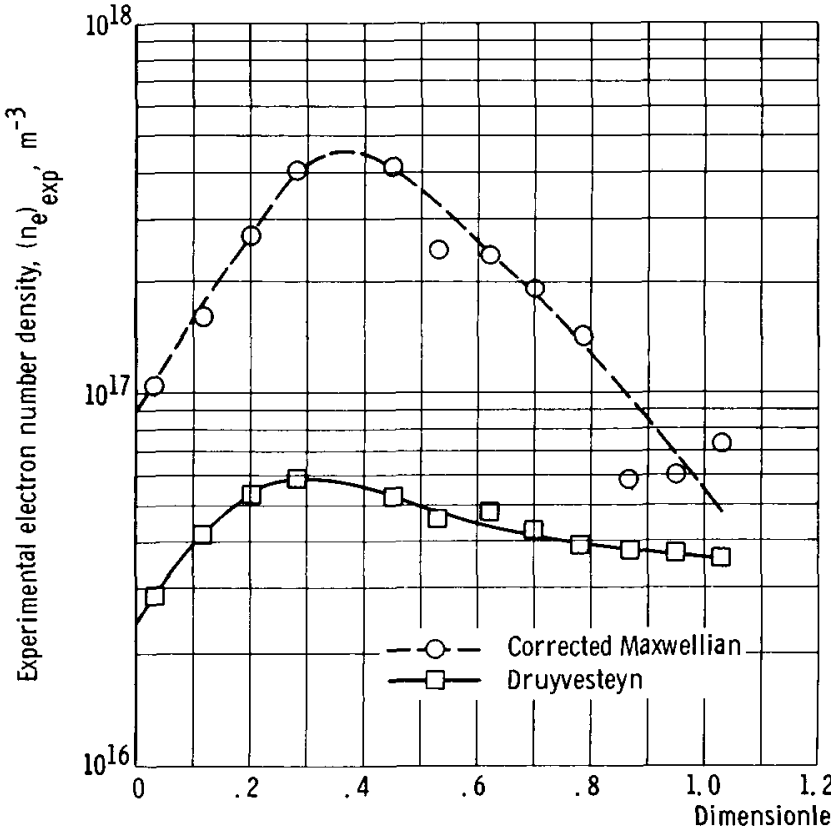

(c) Electron number density.

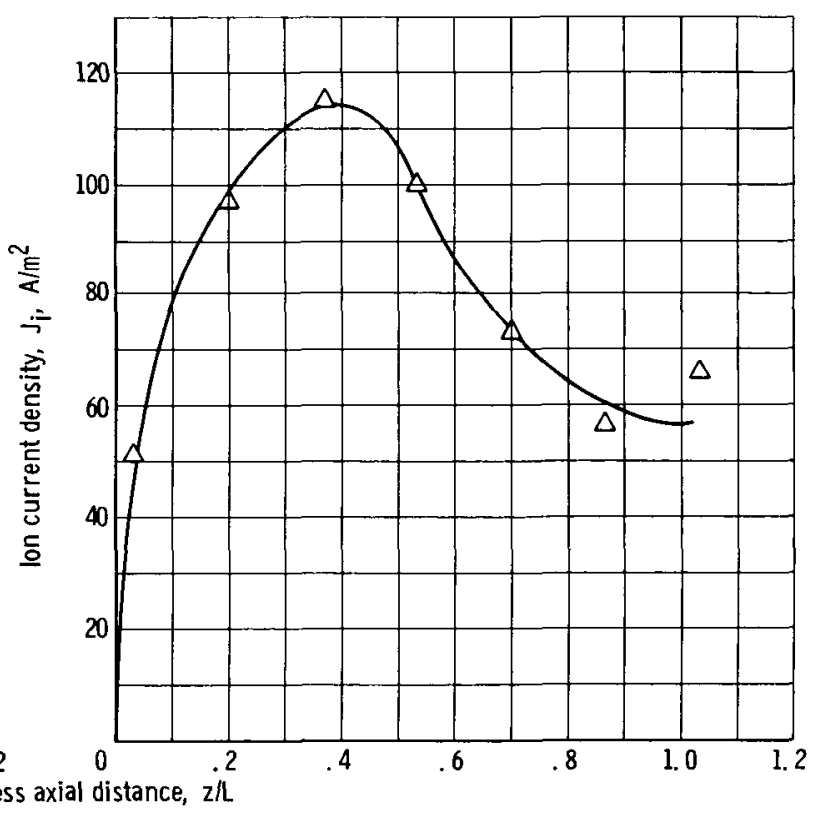

(d) Ion current density. Average ion current density, 82.8 amperes per square meter.

Figure 10, - Continued. 
crease in number density, despite the fact that ions are being accelerated, indicates that ionization is predominant for the first one-third of the accelerator. Near the peak, the corrected Maxwellian electron densities are nearly an order of magnitude greater than Druyvesteyn values. Just as in the case of temperature, the Druyvesteyn and corrected Maxwellian densities approach closer agreement beyond the magnet poles $(z / L>0.7)$.

The results of figures $10(\mathrm{~b})$ and (c) show the importance of the electron pressure gradient term, which was neglected in the theoretical analysis. For $\mathrm{z} / \mathrm{L}<0.2$, both the Druyvesteyn and the corrected Maxwellian data show that

$$
\frac{1}{\mathrm{qn}_{\mathrm{e}}} \frac{\partial\left(\mathrm{n}_{\mathrm{e}} \mathrm{kT}_{\mathrm{e}}\right)}{\partial \mathrm{z}} \sim 800 \mathrm{~V} / \mathrm{m}
$$

compared with $\mathrm{E}_{\mathrm{z}}=1640$ volts per meter. However, for $\mathrm{z} / \mathrm{L}>0.2$, both sets of data show that $\left(1 / q_{\mathrm{e}}\right)\left[\partial\left(\mathrm{n}_{\mathrm{e}} \mathrm{kT} \mathrm{e}\right) / \partial \mathrm{z}\right]<400$ volts per meter. Neglecting this term compared with $E_{z}$ therefore seems justifiable for $z / L>0.2$, but not for $z / L<0.2$.

The ion current density measured with the button probe is shown in figure 10(d). Again, the rising ion current density indicates the importance of ionization for the first one-third of the accelerator. For $0.5 \leq \mathrm{z} / \mathrm{L} \leq 0.8$, the ion current density decreases. The decrease observed in the region $0.5 \leq \mathrm{z} / \mathrm{L} \leq 0.8$ is probably caused by radial flow to the walls rather than recombination. The recombination rate is negligible for the

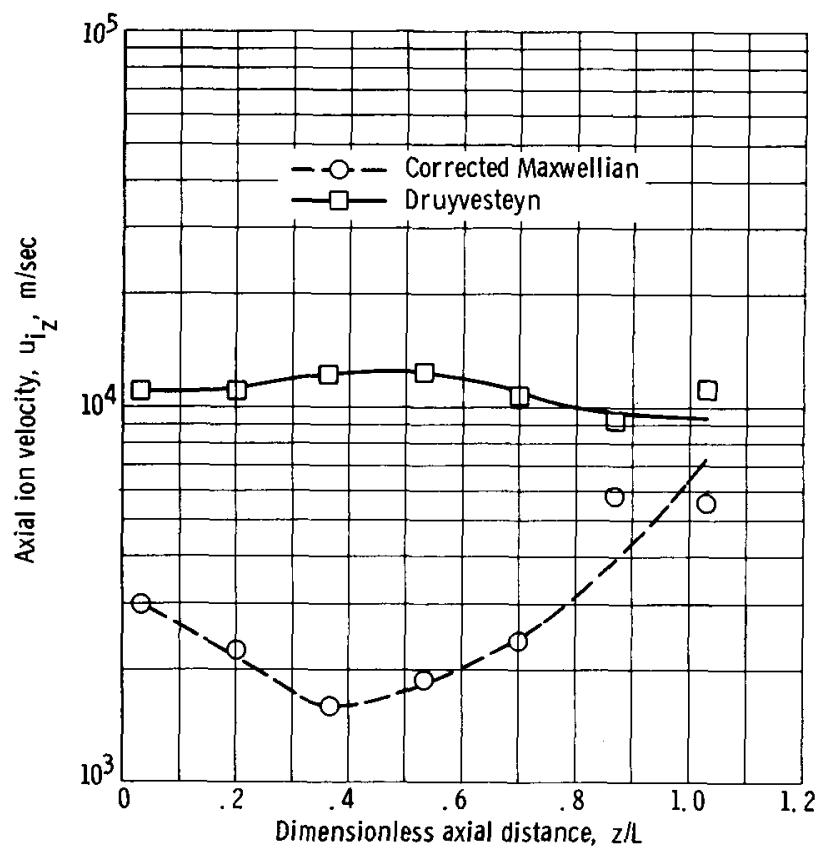

(e) Axial ion velocity.

Figure 10. - Concluded. electron temperatures and number densities existing in the argon Hall accelerator (ref. 18).

With the assumption of equal charge densities, the results of figure $10(\mathrm{~d})$, and the number density from figure 10(c), the ion velocity was computed and is shown in figure 10(e). The criterion for a stable sheath (ref. 17) requires a directed ion velocity toward the button probe of approximately $\sqrt{\mathrm{kT}_{\mathrm{e}} / \mathrm{m}_{\mathrm{i}}}$. Axial ion velocities determined from this criterion for both the corrected Maxwellian and Druyvesteyn data are between 4 to $7 \times 10^{3}$ meters per second. Such velocities would result merely by the presence of the probe even if the plasma were quiescent. This does not mean that the probe caused the measured ion veloci- 
ties, but it does determine a minimum ion velocity that can be measured. It is evident from figure $10(\mathrm{e})$ that the ions are essentially unaccelerated. There are two likely explanations for such a result. First, charge exchange may be responsible. The chargeexchange cross section data for argon (ref. 19, p. 164) were used to compute a mean free path for charge exchange. For all ion energies greater than 25 electron volts, the argon charge-exchange cross section is approximately $30 \times 10^{-16}$ square centimeter. With this value of the cross section and a neutral density of $5.2 \times 10^{19}$ per cubic meter, the following mean free path results:

$$
\lambda=\frac{10^{3}}{(5.2)(30)}=6.41 \mathrm{~cm}
$$

It can be concluded from a comparison of this value of $\lambda$ with the accelerator length, $\mathrm{L}=7.62$ centimeters, that charge exchange is an important mechanism for limiting the ion velocity. Charge exchange is not necessarily a serious inefficiency, since the highspeed neutrals produced are just as efficient in producing thrust as ions of equal speed. The inefficiency that does result from charge exchange is the nonuniformity in velocities at the accelerator exit.

The second possible explanation for the ion velocity results shown in figure 10(e) is that the ions are being accelerated to the accelerator walls where they recombine. Since the radial magnetic field has no effect on the radial motion of the electrons, their centrifugal acceleration will force them to the outer wall of the accelerator. In addition, a radial ambipolar electric field will be established that will also accelerate ions to the walls. With the assumption of a Boltzmann distribution for the electron density, Langmuir and Tonks (ref. 20) have shown, by solving Poisson's equation including ion production, that a potential drop of about $\mathrm{kT}_{\mathrm{e}} / \mathrm{q}$ to $2 \mathrm{kT}_{\mathrm{e}} / \mathrm{q}$ can be established in a cylindrical plasma. This potential drop will accelerate ions to the cylinder walls.

Janes and Dotson (ref. 8) have obtained experimental results for the variation of the ion current and electron number density through a similar accelerator. They measured the ion current $\mathrm{J}_{i_{z}}$ with a plane double Langmuir probe and interpreted the measured force acting on a small quartz plate as the momentum of the accelerated ions $m_{i} n_{i} u_{i}^{2}$. When equal charge densities were assumed and the ion current measurement and the ion momentum measurement were combined, the electron number density $\mathrm{n}_{\mathrm{e}}$ and the ion velocity $u_{i_{z}}$ were obtained. The results of reference 8 are reproduced in figure 11. If charge exchange and location of ionization are important, the interpretation of results will be affected since the momentum measurement will also include the neutral momentum $\mathrm{m}_{\mathrm{o}} \mathrm{N}_{\mathrm{o}} \mathrm{u}_{\mathrm{z}}^{2}$ and the force resulting from the ion velocity distribution, which were assumed to be negligible. The results in figure 11 for $n_{e}$ and $J_{i_{z}}$ variations with axial 


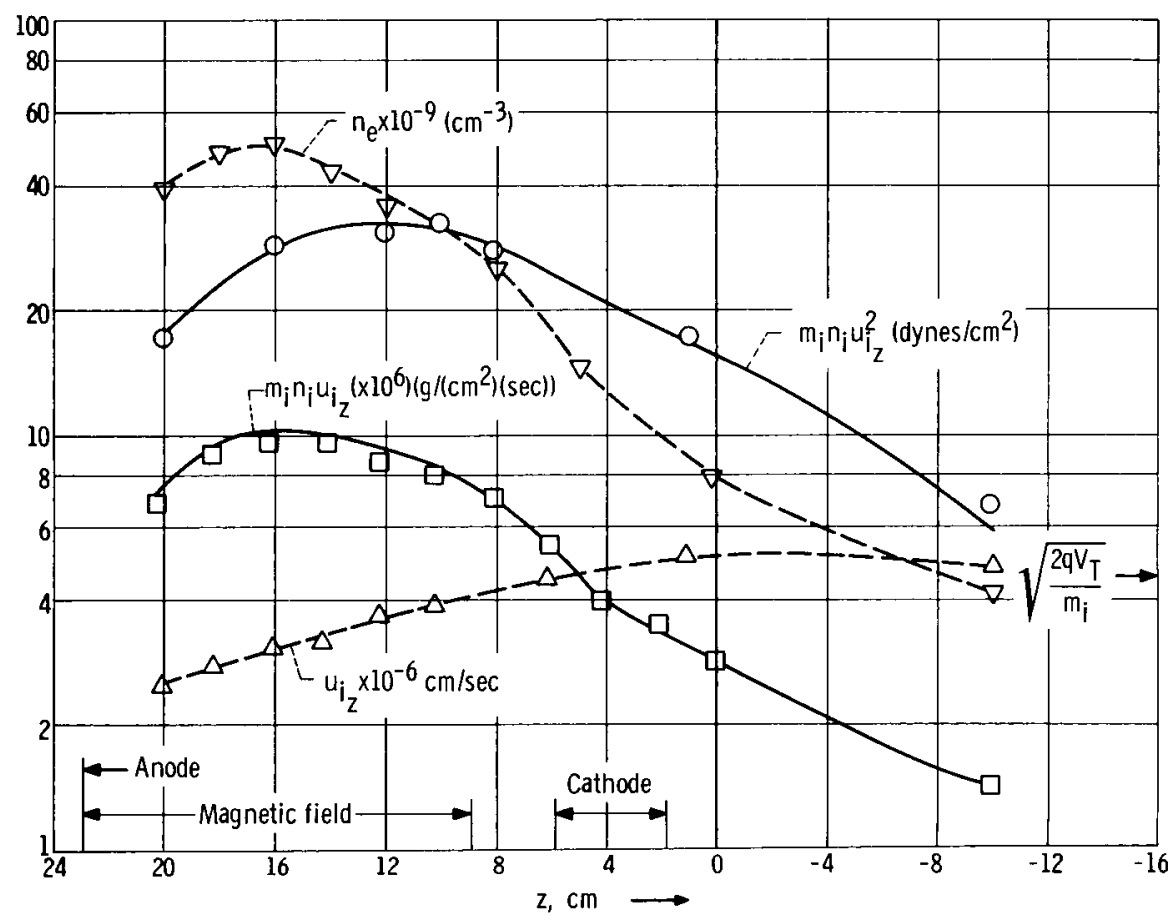

Figure 1l. - Experimental data of reference 8. Mass flow rate, 0.002 gram per second; total current, 10 amperes; total applied voltage, 400 volts.

distance are very similar in shape to those of figures $10(\mathrm{c})$ and (d); however, the results for $u_{i_{z}}$ are quite different from those shown in figure $10(\mathrm{e})$. They indicate that $u_{i_{z}}$ is a monotonically increasing function from the anode to the cathode. The value of $u_{i_{z}}$ at the cathode is given as $\sqrt{2 q V_{T} / m_{i}}$, which would be true only if the ions were accelerated through the potential $\mathrm{V}_{\mathrm{T}}$. Obviously, if the location of ionization and charge exchange were considered the results presented for $u_{i_{z}}$ would be reduced. If charge exchange were to predominate, it would be expected that $u_{i_{z}}$ should decrease near the cathode.

An interesting conclusion can be made from the force measurement of reference 8 . These results, shown in figure 11 as $m_{i} n_{i} u_{i}^{2}$, imply that the force increases at the beginning half of the accelerator and then decreases through the remainder of the accelerator. Since an ion accelerating electric field is maintained through the entire accelerator, it seems reasonable to expect the force to be an increasing function, even if charge exchange is important, unless the plasma momentum is going to the walls. Because Janes and Dotson's results do not show an increasing force, it can be concluded that the plasma momentum is being lost to the walls. This conclusion was also shown from the results shown in figure $10(e)$.

The importance of the electron acceleration term $\partial u_{e_{z}} / \partial z$ can be evaluated by using 
- data presented in figures 10 (c) and (e). From the definition of the total current, an expression for the electron velocity can be derived if equal charge densities are assumed:

$$
J_{T}=q n\left(u_{i_{z}}-u_{e_{z}}\right)
$$

Therefore,

$$
u_{e_{z}}=u_{i_{z}}-\frac{J_{T}}{q n}
$$

and

$$
\frac{\partial \mathrm{u}_{\mathrm{z}}}{\partial \mathrm{z}}=\frac{\partial \mathrm{u}_{\mathrm{z}}}{\mathrm{dz}}+\frac{J_{\mathbf{T}}}{\mathrm{q}} \frac{1}{\mathrm{n}^{2}} \frac{\partial \mathrm{n}}{\partial \mathrm{z}}
$$

From the results of figures 10 (c) and (e), the first term in equation (35) can be shown to be small compared with the second term. Therefore, the number density curves (fig. 10 (c)) show that the largest values of $\partial \mathrm{u}_{e_{\mathrm{z}}} / \partial \mathrm{z}$ occur in the region $\mathrm{z} / \mathrm{L}<0.2$. In this region

$$
\frac{\partial \mathrm{u}_{\mathrm{z}}}{\partial \mathrm{z}} \approx \frac{\mathrm{J}_{\mathrm{T}}}{\mathrm{q}} \frac{1}{\mathrm{n}^{2}} \frac{\partial \mathrm{n}}{\partial \mathrm{z}} \sim 10^{6}
$$
In order to neglect the term $\partial \mathrm{u}_{\mathrm{z}} / \partial \mathrm{z}$ in equation (4), the following condition must be
satisfied:

$$
\frac{1}{\nu_{\mathrm{eo}}} \frac{\partial \mathrm{u}_{\mathrm{e}}}{\partial \mathrm{z}} \ll 1
$$

For $\mathrm{N}_{\mathrm{O}} \sim 5 \times 10^{19}$ per cubic meter and $\mathrm{kT} \mathrm{e}^{/ \mathrm{q}} \geq 10$ electron volts figure 2 shows that $\nu_{\mathrm{eo}} \sim 10^{7}$. Therefore,

$$
\frac{1}{\nu_{\mathrm{eo}_{\mathrm{m}}}} \frac{\partial \mathrm{u}_{\mathrm{z}}}{\partial \mathrm{z}} \sim \frac{10^{6}}{10^{7}}=0.1
$$


As a result, it seems reasonable to neglect the term $\left(1 / \nu_{\mathrm{eo}}\right)\left(\partial \mathrm{u}_{\mathrm{e}} / \partial \mathrm{z}\right)$ in equation (4).

\section{Experimental Evidence of Anomalous Diffusion}

To check the validity of the classical expression for electron current density across the magnetic field (eq. (7)), the data of figure 10 were used. If $\left(\omega_{\mathrm{e}} / \nu_{\mathrm{eo}}\right)>>1$ and the neutral velocity term is neglected, equation (7) gives the following result for the electron current density:

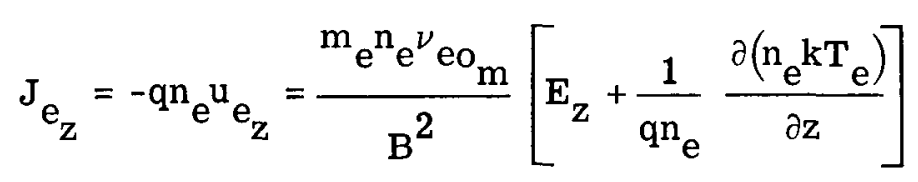

Both Druyvesteyn and corrected Maxwellian data were used to compute $J_{e_{z}}$. The largest values of $\mathrm{J}_{\mathrm{z}}$ occur at $\mathrm{z} / \mathrm{L}=0.3$ for the Druyvesteyn data and at $\mathrm{z} / \mathrm{L}=0.35$ for the corrected Maxwellian data. At these axial stations, the electron current density from Druyvesteyn data at a magnetic field of 200 gauss is

$$
\left(\mathrm{J}_{\mathrm{z}}\right)_{\mathrm{DR}}=2.23 \mathrm{~A} / \mathrm{m}^{2}
$$

and from corrected Maxwellian data is

$$
\left(\mathrm{J} \mathrm{e}_{\mathrm{z}}\right)_{\mathrm{MAX}}=21.2 \mathrm{~A} / \mathrm{m}^{2}
$$

In computing $\mathrm{J}_{\mathrm{e}_{\mathrm{z}}}$, the values of $\nu_{\mathrm{eo}_{\mathrm{m}}}$ were obtained from figure 2 (p. 4). It should be remembered that $\nu_{\mathrm{eo}}$ is based on a Maxwellian distribution. However, unless the distribution function is far from being Maxwellian, the correct value of the collision frequency, which is obtained by integrating over all velocity space, should not be much different from one based on a Maxwellian distribution.

To obtain the experimental value of $J_{e_{z}}$ it was assumed that the total current was uniform across the accelerator, therefore, $\mathrm{J}_{\mathrm{T}}=289$ amperes per square meter. Thus, from figure 10 (d) at $\mathrm{z} / \mathrm{L}=0.35$, the experimentally determined electron current densities are as follows: 


$$
\begin{aligned}
& \left(J_{e_{z}}\right)_{\exp }=179 \mathrm{~A} / \mathrm{m}^{2} \text { at } \mathrm{z} / \mathrm{L}=0.3 \\
& \left(\mathrm{~J}_{\mathrm{e}}\right)_{\exp }=175 \mathrm{~A} / \mathrm{m}^{2} \text { at } \mathrm{z} / \mathrm{L}=0.35
\end{aligned}
$$

Based on the large differences between the calculated current densities and the experimental values, it would appear that there is an anomalous mechanism which allows the electrons to diffuse across the magnetic field at a rate much greater than that predicted classically.

Further evidence leading to the conclusion that an anomalous electron diffusion exists was obtained by measuring the effective Hall parameter $\omega_{\mathrm{e}} \tau_{\mathrm{e}}$. The ion current density distribution was measured for several values of the magnetic field with the button probe. In all cases the distribution had a form similar to that shown in figure 10(d). From these distributions, average ion current densities $\bar{J}_{i_{z}}$ were computed and the results combined with the measured Hall currents to compute an average value of $\overline{\omega_{\mathrm{e}} \mathrm{e}_{\mathrm{e}}}$ for the accelerator

$$
\overline{\omega_{\mathrm{e}}{ }^{\mathrm{e}} \mathrm{e}}=\frac{\overline{\mathbf{J}}_{\mathrm{e}_{\theta}}}{\overline{\mathbf{J}}_{\mathrm{e}_{\mathbf{z}}}}=\frac{\mathrm{J}_{\text {Hall }}}{\mathrm{J}_{\mathbf{T}}-\overline{\mathrm{J}}_{\mathbf{i}_{\mathbf{z}}}}
$$

These values of $\overline{\omega_{\mathrm{e}} \tau_{\mathrm{e}}}$ are listed in table $\mathrm{I}$.

An effective value of $\omega_{e} e_{e}$ can also be obtained from the measured plasma properties. Neglecting the pressure gradient term in equation (36) gives the following result:

$$
\omega_{e^{\tau} e}=\frac{q n_{e}}{J_{e_{z}}} \frac{E_{z}}{B}=\frac{q n_{e}}{J_{T}-J_{i_{z}}} \frac{E_{z}}{B}
$$

Experimentally determined values of $\mathrm{n}_{e}$ and $\mathrm{J}_{\mathbf{i}_{\mathbf{z}}}$ were used in equation (37) to compute the effective Hall parameters at $\mathrm{z} / \mathrm{L}=0.367$ for several magnetic field strengths. The results from both Maxwellian and Druyvesteyn reduced data are shown in table I. For all cases listed, $\mathrm{J}_{\mathrm{T}}=289$ amperes per square meter and $\mathrm{N}_{\mathrm{O}}=5.2 \times 10^{19}$ per cubic meter.

The values of $\alpha$ for the Druyvesteyn data and $\bar{\alpha}$ from the Hall current data com- 


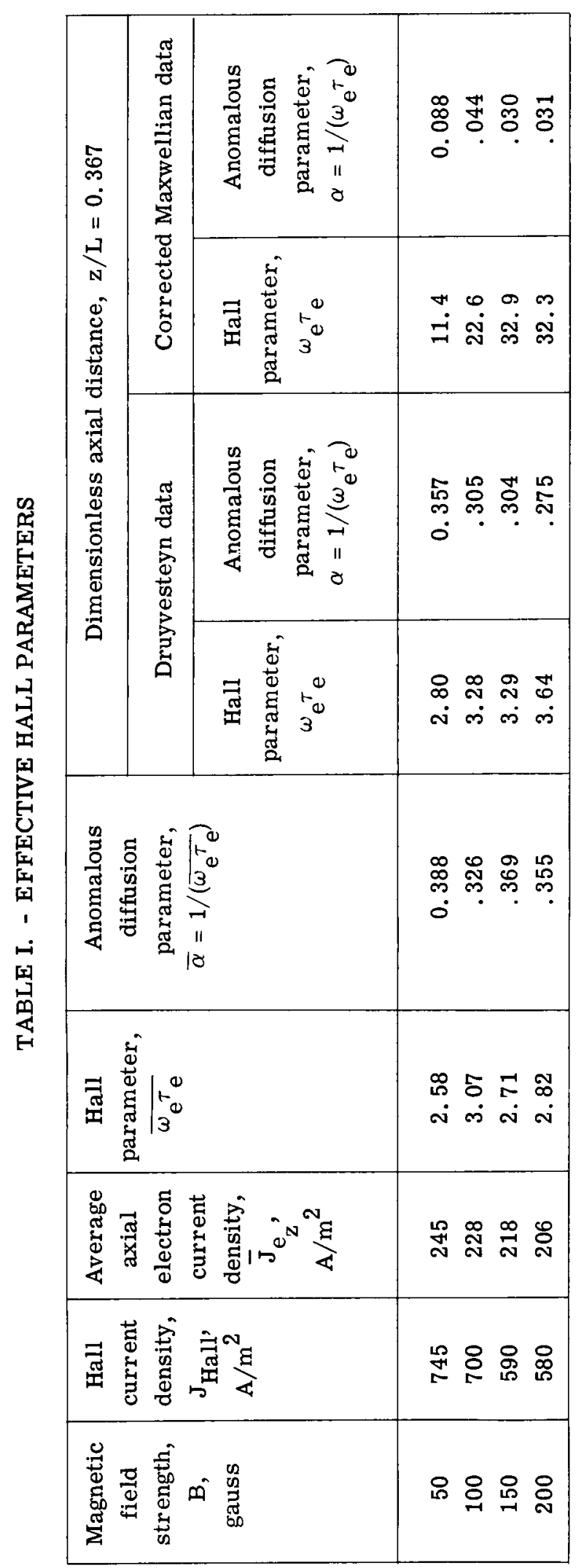




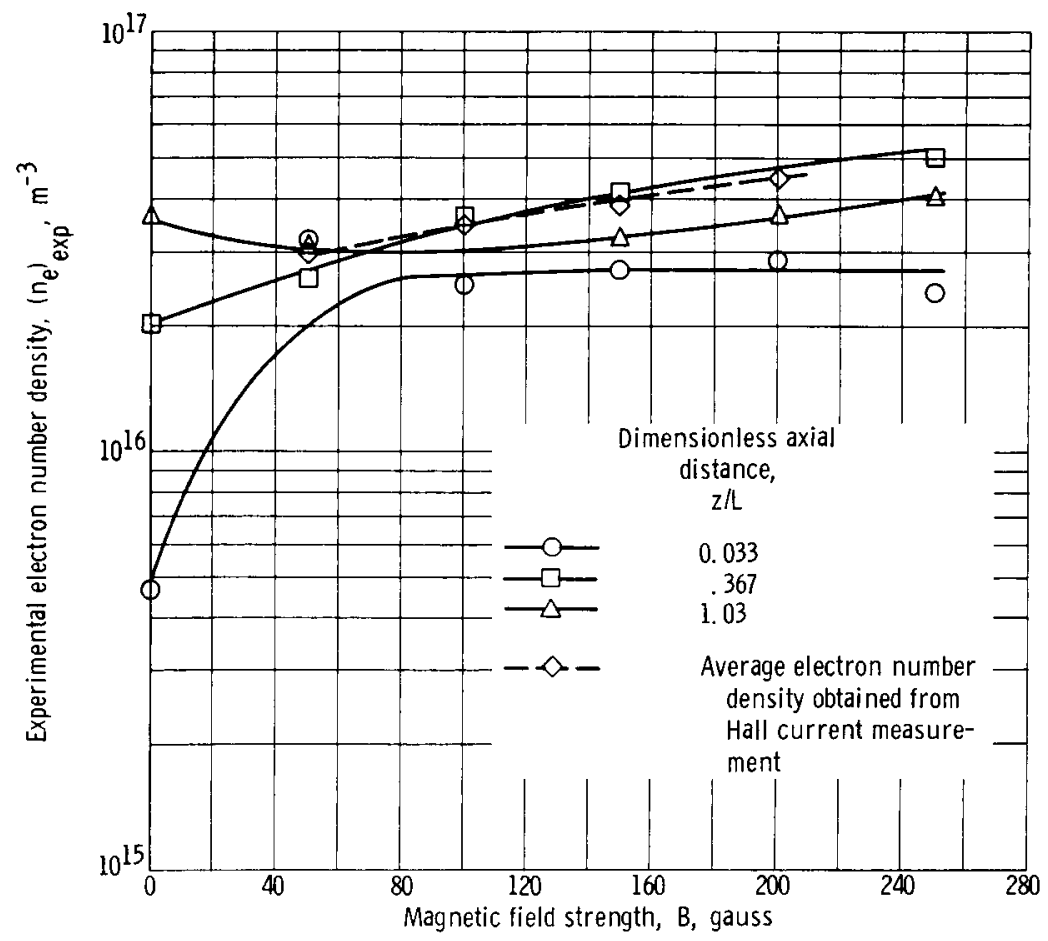

Figure 12. - Dependence of electron number density on magnetic field. Total current density, 289 amperes per square meter; neutral number density, $5.2 \times 10^{19}$ per cubic meter; accelerator length, 7.62 centimeters.

pare closely with the value of $\alpha=1 / 3$ presented in reference 8 . If figure 2 is used to obtain $\nu_{\mathrm{eo}}$, the classical value of $\omega_{\mathrm{e}} / \nu_{\mathrm{eo}}$ should be of the order of 100 for the electron temperatures, neutral densities, and magnetic fields obtained in the argon Hall accelerator. As a result of the large discrepancies between the measured values of $\omega_{\mathrm{e}} \mathrm{e}_{\mathrm{e}}$ and $\mathrm{J}_{\mathrm{e}_{\mathrm{z}}}$ and classically computed values of these parameters, it appears that some anomalous phenomena occur to produce enhanced diffusion of the electrons across the magnetic field.

\section{Dependence of Plasma Properties on Magnetic Field}

Experimental. - In figure 12 the experimentally determined variation of the electron number density with magnetic field for constant total current density $\mathrm{J}_{\mathrm{T}}=289$ amperes per square meter at axial stations $\mathrm{z} / \mathrm{L}=0.033,0.367$, and 1.03 is presented. Only the Druyvesteyn determined values for the density are shown. Maxwellian values for the density are nearly an order of magnitude greater, but show the same variation with magnetic field. Also shown in figure 12 is the mean number density determined from the measured Hall current. As can be seen, there is good agreement between the number 


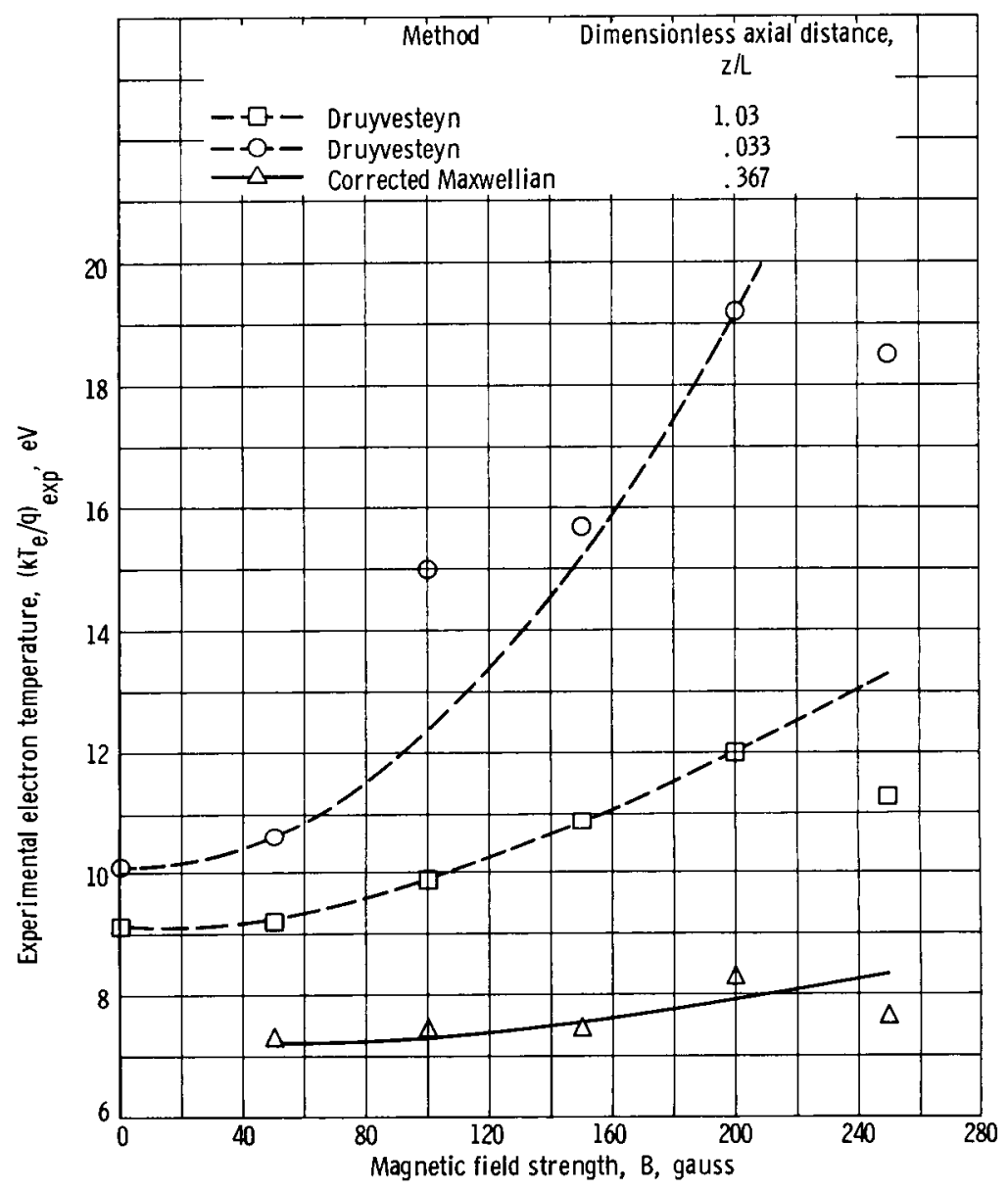

Figure 13. - Experimental electron temperatures. Total current density, 289 amperes per square meter; neutral number density, $5.2 \times 10^{19}$ per cubic meter.

densities determined by the Druyvesteyn method and the Hall current measurement.

The experimentally determined dependence of the electron temperature and the electric field on magnetic field is illustrated in figures 13 and 14, respectively. Both Maxwellian and Druyvesteyn data show some increase in electron temperature with magnetic field. From figure 14 it appears that the electric field increases with the magnetic field.

Theoretical. - Results for the electric field that were obtained from the classical diffusion analysis (eq. (15)), are shown in figure 15. Comparison of the experimental results in figure 14 with those in figure 15 shows that the results for classical diffusion predict much larger electric fields than those measured.

Theoretical results for the electric field under the assumption of anomalous electron diffusion are shown in figure 14. The electric field was calculated from equation (19) with $\alpha=1 / 3$ and $\mathrm{N}_{\mathrm{O}}=5.2 \times 10^{19}$ per cubic meter. Figure 14 shows that an electron tem- 


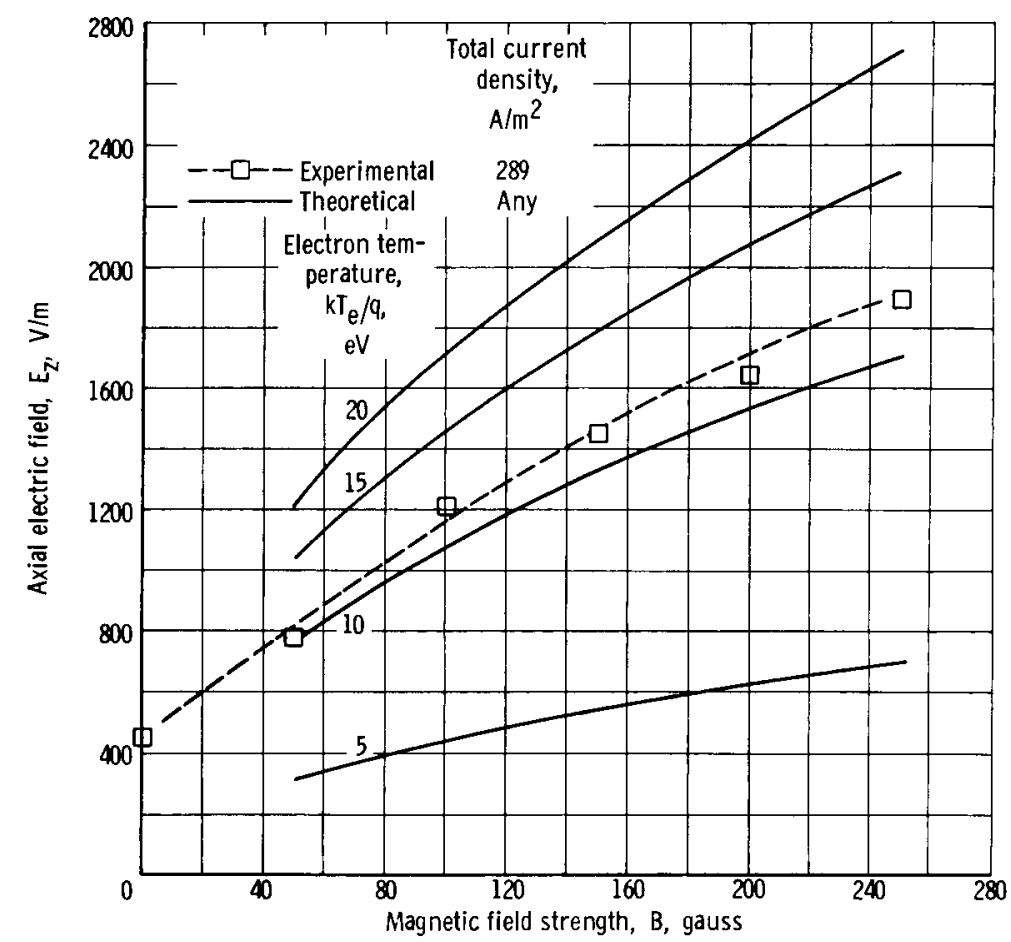

Figure 14. - Comparison of experimental and theoretical electric field for anomalous diffusion. Effective Hall parameter, 3; neutral number density, 5. 2x1019 per cubic meter.

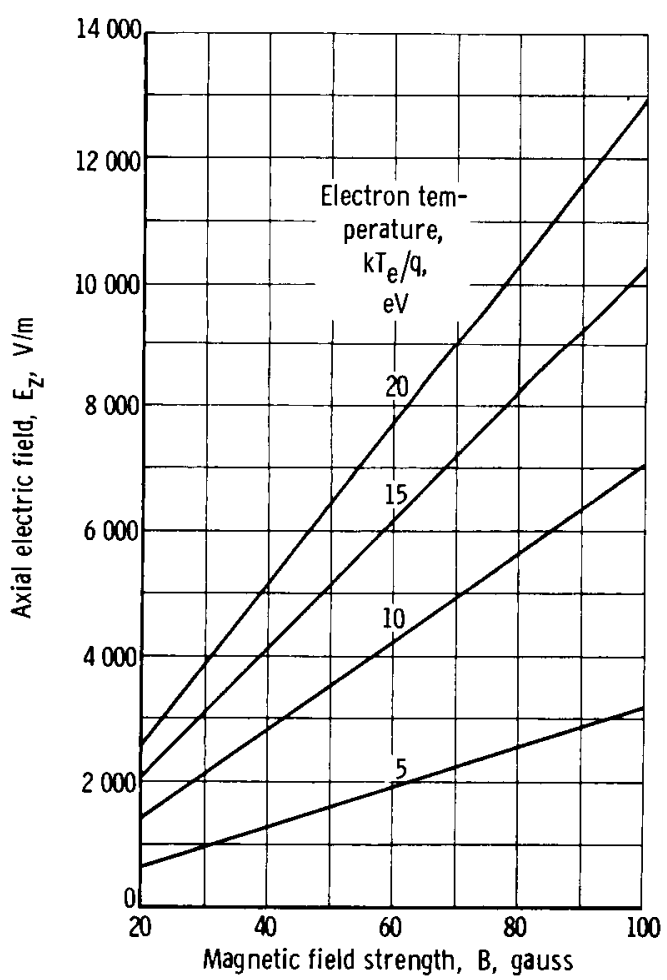

Figure 15. - Variation of electric field with magnetic field for classical diffusion. perature between 10 and 15 electron volts gives good agreement between the experimental electric fields and the fields calculated. From figure 13 it is evident that these electron temperatures are generally in agr eement although slightly less than Druyvesteyn temperatures and do not agree with the corrected Maxwellian temperatures. Part of the discrepancy for the Druyvestian case may result from the derivation of the ionization and excitation collision frequencies $\nu_{\mathrm{I}}$ and $\nu_{\text {ex }}$. As pointed out previously, $\nu_{\mathrm{I}}$ and $\nu_{\text {ex }}$ depend primarily on the high-energy tail of the distribution function. If the actual distribution is depleted in this region, the actual temperature must be higher than a Maxwellian temperature to produce the same value of $\nu_{\mathrm{I}}$ and $\nu_{\text {ex }}$. Therefore, the temperature will also be higher to produce the same electric field as a Maxwellian distribution (eq. (19)). 


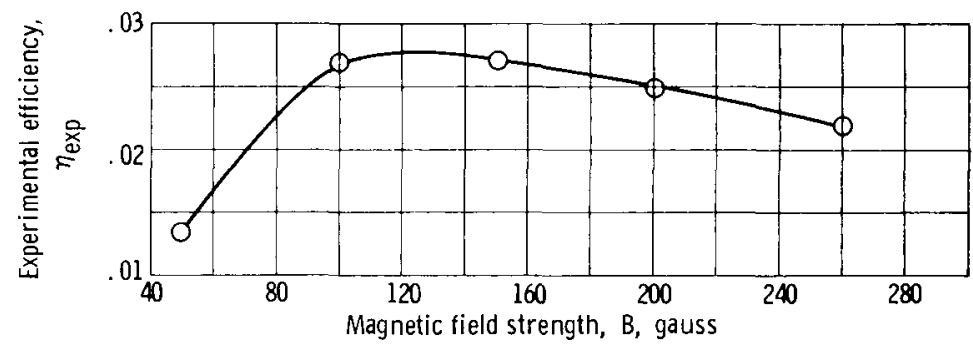

Figure 16. - Experimental accelerator efficiency. Total current density, 289 amperes per square meter; neutral number density, $5.2 \times 10^{19}$ per cubic meter.

\section{Experimental Accelerator Efficiency}

From the experimentally determined values of the ion current density and the Druyvesteyn determined electron number density at $\mathrm{z} / \mathrm{L}=1.0$, an accelerator efficiency can be computed. To make the calculation, it was assumed that, at the accelerator exit, the plasma has equal charge densities $n_{e}=n_{i}$ and that the ion velocity and number density were uniform. It was also assumed that the total current density $\mathrm{J}_{\mathrm{T}}$ was uniform across the accelerator. Under these conditions, the efficiency is

$$
\eta_{\exp }=\frac{\frac{1}{2}\left(\mathrm{~m}_{\mathrm{i}} \mathrm{n}_{\mathrm{i}} \mathrm{u}_{\mathrm{i}_{\mathrm{z}}}^{3}\right)_{\mathrm{z}=\mathrm{L}}}{\mathrm{V}_{\mathrm{T}} \mathrm{I}_{\mathrm{T}}}=\frac{\mathrm{m}_{\mathrm{i}}}{2 \mathrm{q}} \frac{\mathrm{u}_{\mathrm{z}=\mathrm{L}}}{\mathrm{V}_{\mathrm{T}}} \frac{\mathrm{J}_{\mathrm{i}_{\mathrm{z}=\mathrm{L}}}}{\mathrm{J}_{\mathrm{T}}}
$$

In figure 16, the experimental efficiency is presented. It can be seen that the magnetic field had little effect on the efficiency for $B>100$ gauss. This seems to substantiate that momentum and energy transfer to the walls are the important loss mechanisms. With the radial magnetic field, both electrons and ions are free to move along the field lines to the walls, so that the magnetic field strength should have little effect on energy and momentum transfer to the walls. It should be remembered that the efficiency defined by equation (38) does not include the momentum of high-speed neutrals produced by charge exchange. If this were included the efficiency would be higher.

\section{CONCLUSION}

The experimentally determined axial electron current moving perpendicular to the magnetic field lines was at least an order of magnitude greater than the classically computed result. This result, together with the fact that measured values of the effective 
. Hadl parameter were much lower than expected, implies that an anomalous electron diffusion across the magnetic field exists. Theoretical results for the variation of electric field with magnetic field that include anomalous electron diffusion agree well with the experimental results. At constant current it was found that the electric field increases with magnetic field.

Experimental results indicate that the ions are not being accelerated to velocities that would be attained if the ions were to undergo electrostatic acceleration through the applied potential. Charge exchange is a possible explanation for this result. However, since Janes and Dotson measured a decrease in the axial plasma momentum, it appears that the plasma momentum is being lost to the walls.

The experimentally determined accelerator efficiency is essentially independent of magnetic field equal to or greater than 100 gauss. The independence substantiates the conclusion that ion momentum and energy transfer to the walls are the most important loss mechanisms.

Lewis Research Center,

National Aeronautics and Space Administration, Cleveland, Ohio, September 17, 1965. 


\section{SYMBOLS}

\begin{tabular}{|c|c|c|c|}
\hline A & probe surface area & $\mathrm{R}_{\mathrm{o}}$ & outer radius of accelerator \\
\hline B & magnetic field strength & $\mathbf{r}$ & radial coordinate \\
\hline $\overrightarrow{\mathrm{c}}$ & particle random velocity, $\overrightarrow{\mathrm{v}}-\overrightarrow{\mathrm{u}}$ & $\mathrm{r}_{\mathrm{D}}$ & Debye length \\
\hline $\mathbf{E}$ & electric field strength & $\mathbf{T}$ & temperature \\
\hline $\mathbf{F}$ & velocity distribution function & $\mathrm{U}$ & difference between plasma poten- \\
\hline $\overrightarrow{\mathrm{g}}$ & $\begin{array}{l}\text { relative velocity between two } \\
\text { colliding particles }\end{array}$ & & $\begin{array}{l}\text { tial and Langmuir probe poten- } \\
\text { tial, } V_{P L}-V_{P}\end{array}$ \\
\hline $\mathrm{I}_{\mathrm{T}}$ & total current & $\overrightarrow{\mathrm{u}}$ & average velocity, $\frac{1}{n} \int_{\vec{v}} \vec{v} F d^{3} v$ \\
\hline$i_{e}$ & $\begin{array}{l}\text { electron current collected by } \\
\text { Langmuir probe }\end{array}$ & $\begin{array}{l}\mathrm{V} \\
\rightarrow\end{array}$ & voltage \\
\hline${ }^{i_{P}}$ & $\begin{array}{l}\text { current collected by Langmuir } \\
\text { probe }\end{array}$ & $\overrightarrow{\mathrm{V}}$ & $\begin{array}{l}\text { center-of-mass velocity in binary } \\
\text { collision }\end{array}$ \\
\hline $\mathrm{J}$ & current density & $\mathrm{v}_{\mathrm{T}}$ & $\begin{array}{l}\text { total applied voltage measured } \\
\text { with respect to ground }\end{array}$ \\
\hline $\mathrm{J}_{\mathrm{T}}$ & total current density & $\overrightarrow{\mathrm{v}}$ & total particle velocity, $\overrightarrow{\mathrm{u}}+\overrightarrow{\mathrm{c}}$ \\
\hline k & $\begin{array}{l}\text { Boltzmann constant, } \\
\quad 1.3805 \times 10^{-23} \mathrm{~J} /{ }^{\circ} \mathrm{K}\end{array}$ & z & axial coordinate \\
\hline $\mathbf{L}$ & accelerator length, $7.62 \mathrm{~cm}$ & $\alpha$ & anamolous diffusion parameter \\
\hline $\mathrm{m}$ & particle mass & $\Delta$ & inelastic energy loss increment \\
\hline $\mathrm{N}_{\mathrm{O}}$ & neutral number density & $\epsilon$ & azimuthal scattering angle \\
\hline $\mathrm{n}$ & number density & $\eta$ & accelerator efficiency \\
\hline$p$ & pressure, $\frac{1}{3} \mathrm{~m} \int_{\overrightarrow{\mathrm{v}}} \mathrm{c}^{2} \mathrm{~F} \mathrm{~d} \mathrm{~d}^{3} \mathrm{v}$ & $\begin{array}{l}\theta \\
\kappa_{\mathrm{eo}}\end{array}$ & $\begin{array}{l}\text { azimuthal coordinate } \\
\text { average energy lost by electron }\end{array}$ \\
\hline $\overrightarrow{\mathbf{Q}}$ & $\begin{array}{l}\text { heat flow vector, } \\
\frac{1}{2} \mathrm{~m} \int_{\overrightarrow{\mathrm{v}}} \mathrm{c}^{2} \overrightarrow{\mathrm{c}} \mathrm{F} \mathrm{d} \mathrm{d}^{3} \mathrm{v}\end{array}$ & $\mu$ & $\begin{array}{l}\text { in colliding with neutral, } \\
\text { eq. (12) } \\
\text { reduced mass }\end{array}$ \\
\hline $\mathrm{q}$ & $\begin{array}{l}\text { electron charge, } \\
1.602 \times 10^{-19} \mathrm{C}\end{array}$ & $\nu_{\mathrm{ei}}$ & $\begin{array}{l}\text { electron-ion momentum transfer } \\
\text { collision frequency }\end{array}$ \\
\hline & inner radius of accelerator & & \\
\hline
\end{tabular}




\begin{tabular}{|c|c|c|c|}
\hline$\nu_{\mathrm{eo}}$ & $\begin{array}{l}\text { electron-neutral momentum } \\
\text { transfer collision frequency }\end{array}$ & $\begin{array}{l}\mathrm{DR} \\
\mathrm{e}\end{array}$ & $\begin{array}{l}\text { Druyvesteyn data } \\
\text { electrons }\end{array}$ \\
\hline$\nu_{\mathrm{ex}}$ & excitation collision frequency & el & elastic process \\
\hline$\nu_{\mathrm{I}}$ & ionization collision frequency & ex & excitation process \\
\hline$\sigma_{\mathrm{d}}$ & differential cross section & $\exp$ & experimental \\
\hline$\sigma_{\mathrm{m}}$ & $\begin{array}{l}\text { total momentum transfer cross } \\
\text { section }\end{array}$ & Hall & Hall current \\
\hline$\sigma_{\mathrm{T}}$ & total cross section & $\begin{array}{l}\text { I } \\
\text { i }\end{array}$ & $\begin{array}{l}\text { ionization process } \\
\text { ions }\end{array}$ \\
\hline$\tau$ & time & MAX & corrected Maxwellian data \\
\hline$\tau_{\mathrm{e}}$ & effective electron collision time & o & neutrals \\
\hline$\varphi_{\mathrm{ex}}$ & $\begin{array}{l}\text { excitation potential for first ex- } \\
\text { cited level of neutral }\end{array}$ & $\begin{array}{l}\mathbf{P} \\
\mathbf{P L}\end{array}$ & $\begin{array}{l}\text { probe } \\
\text { plasma }\end{array}$ \\
\hline$\varphi_{\mathbf{I}}$ & ionization potential & $\mathbf{r}$ & radial direction \\
\hline$x$ & scattering angle & $\mathbf{s}$ & species $\mathbf{s}$ \\
\hline $\overrightarrow{\vec{\psi}}$ & stress tensor, $m \int_{\overrightarrow{\mathrm{y}}} \overrightarrow{\mathrm{c}} \overrightarrow{\mathrm{c}} \mathrm{F} \mathrm{d} \mathrm{d}^{3} \mathrm{v}$ & $\mathrm{t}$ & species $t$ \\
\hline$\omega_{\mathrm{e}}$ & electron cyclotron frequency & $\begin{array}{l}\mathbf{z} \\
\theta\end{array}$ & $\begin{array}{l}\text { axial direction } \\
\text { azimuthal direction }\end{array}$ \\
\hline
\end{tabular}

Subscripts:

coll collision 


\section{ELECTRON EQUATION OF MOTION ${ }^{1}$}

If the zeroth moment of the Boltzmann equation is taken the following result is obtained:

$$
\frac{\partial\left(\mathrm{n}_{\mathrm{s}} \mathrm{m}_{\mathrm{S}}\right)}{\partial \mathrm{t}}+\nabla \cdot\left(\mathrm{m}_{\mathbf{s}} \mathrm{n}_{\mathrm{s}} \overrightarrow{\mathrm{u}}_{\mathrm{s}}\right)=\sum_{\mathrm{t}} \int_{\overrightarrow{\mathrm{v}}_{\mathrm{s}}}\left(\frac{\partial \mathbf{F}_{\mathrm{s}}}{\partial \tau}\right)_{t_{\text {coll }}} \mathrm{m}_{\mathrm{s}} \mathrm{d}^{3} \mathrm{v}_{\mathrm{s}}
$$

where the right side of equation (B1) represents the rate of production of species $\mathbf{s}$ by collisional processes such as ionization, and $\mathrm{F}_{\mathrm{S}}\left(\overrightarrow{\mathrm{v}}_{\mathrm{S}}, \overrightarrow{\mathrm{r}}, \tau\right)$ is the distribution function of species $s$. If no production occurred, the right side would be zero, and the usual continuity equation would result (eq. (6-8) of ref. 7, p. 157). Other terms appearing in equation (B1) are the number density $n_{s}$, the particle mass $m_{s}$, the particle velocity $\vec{v}_{s}$, and the average velocity $\vec{u}_{\mathbf{S}}$.

Taking the first moment of the Boltzmann equation, as in reference 21 (eq. (6-9), p. 157), results in the following expression:

$$
\begin{aligned}
& \frac{\partial\left(n_{s} m_{s} \vec{u}_{s}\right)}{\partial t}+\left(n_{s} m_{s} \vec{u}_{s} \cdot \nabla\right) \vec{u}_{s}+\vec{u}_{s} \nabla \cdot\left(n_{s} m_{s} \vec{u}_{s}\right) \\
& \\
& +\nabla \cdot \vec{\psi}_{s}-n_{s} q_{s}\left(\vec{E}+\vec{u}_{s} \times \vec{B}\right)
\end{aligned}
$$

The term on the right side of equation (B2) represents the momentum gained by species $s$ in collisions with all the other species $t$ in the plasma, and $\vec{\psi}_{s}=m_{s} \int_{\vec{v}_{s}} \vec{c}_{s} \vec{c}_{s} F_{s} d^{3} v_{s}$ is the stress tensor of species s. Also appearing in equation (B2) are the charge of species $s, q_{s}$, electric field $\vec{E}$, and magnetic field $\vec{B}$.

If equation (B1) is multiplied by $\overrightarrow{\mathrm{u}}_{\mathrm{S}}$ and the result subtracted from equation (B2), the

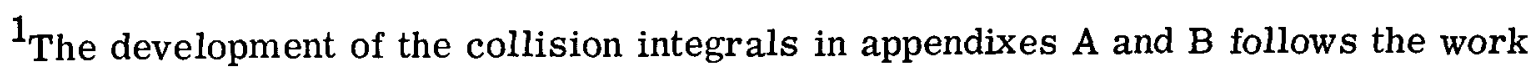
of Dr. Frederic A. Lyman presented in unpublished lecture notes at Lewis. In his work, however, only elastic collisions are considered. 
- following equation of motion for species $s$ is obtained

$$
m_{s} n_{s} \frac{\partial \vec{u}_{s}}{\partial \tau}+n_{s} m_{s}\left(\vec{u}_{s} \cdot \nabla\right) \vec{u}_{s}+\nabla \cdot \vec{\psi}-n_{s} q_{s}\left(\vec{E}+\vec{u}_{s} \times \vec{B}\right)=\sum_{t} \int_{\vec{v}_{s}}\left(\frac{\partial F_{s}}{\partial \tau}\right)_{t_{c o l l}} m_{s} \vec{c}_{s} d^{3} v_{s}
$$

where the definition $\vec{v}_{s}=\vec{u}_{S}+\vec{c}_{s}$ has been used in equation (B2). In order to obtain a useful form of equation (B3), the right side of equation (B3), which represents the momentum gained by species $s$ in collisions with the other species in the plasma, must be evaluated.

From reference 22 (p. 62, section 3.51), the rate of change in momentum of species $\mathrm{s}$ in collisions with all other species can be written as

$$
\begin{aligned}
& \sum_{\mathrm{t}} \int_{\overrightarrow{\mathrm{v}}_{\mathrm{s}}}\left(\frac{\partial \mathrm{F}}{\partial \tau}\right)_{\mathrm{t}_{\mathrm{soll}}} \mathrm{m}_{\mathrm{s}} \overrightarrow{\mathrm{c}}_{\mathrm{s}} \mathrm{d}^{3} \mathrm{v}_{\mathrm{s}} \\
& =\int_{t} \int_{\vec{v}_{s}} \int_{\vec{v}_{t}}^{\pi} \int_{x=0}^{2 \pi} \int_{\epsilon=0}^{3} v^{3} d^{3} v_{t^{m}} m_{s}\left(\vec{c}_{s}^{\prime}-\vec{c}_{s}\right) F_{s} F_{t} g \sigma_{d}(g, x) \sin \chi d \chi d \epsilon
\end{aligned}
$$

where a prime denotes the condition after a collision, $g$ is the relative speed $\left|\vec{v}_{t}-\vec{v}_{s}\right|$, $\chi$ is the scattering angle, $\epsilon$ is the azimuthal scattering angle, and $\sigma_{d}$ is the differential cross section. The following notation is used for integration over velocity space:

$$
\int_{\vec{v}}(\cdot \cdot) d^{3} v=\int_{-\infty}^{+\infty} \int_{-\infty}^{+\infty} \int_{-\infty}^{+\infty}(\cdot \cdot) d v_{x} d v_{y} d v_{z}
$$

The first step in carrying out the integration of the right side of equation (B4) is relating $\left(\overrightarrow{\mathrm{c}}_{\mathbf{s}}^{\prime}-\overrightarrow{\mathbf{c}}_{\mathbf{s}}\right)$ to $\mathrm{g}, \chi$, and $\epsilon$. For a binary inelastic collision, where any particles that may be produced are assumed to have negligible momentum and energy, the conservation of momentum and energy can be expressed as follows:

$$
m_{s} \vec{v}_{s}+m_{t} \vec{v}_{t}=m_{s} \vec{v}_{s}^{s}+m_{t} \vec{v}_{t}^{\prime}
$$




$$
\frac{1}{2} m_{s} v_{s}^{2}+\frac{1}{2} m_{t} v_{t}^{2}=\frac{1}{2} m_{s} v_{s}^{\prime 2}+\frac{1}{2} m_{t} v_{t}^{\prime 2}+\Delta
$$

where $\Delta$ is the energy lost in the inelastic process. If the center-of-mass velocity is defined as $\vec{v}=\frac{m_{s} \vec{v}_{s}+m_{t} \vec{v}_{t}}{m_{t}+m_{t}}$, the conservation of momentum shows that $\vec{v}=\vec{v}^{\prime}$. Writing $\vec{v}_{s}, \vec{v}_{s}^{\prime}, \vec{v}_{t}$, and $\vec{v}_{t}^{\prime}{ }^{\prime}+m_{t}$ in terms of the center-of-mass velocity and the relative velocities results in

$$
\begin{aligned}
& \vec{v}_{s}=\vec{v}-\frac{m_{t}}{M} \vec{g} \\
& \vec{v}_{s}^{\prime}=\vec{v}-\frac{m_{t}}{M} \vec{g}^{\prime} \\
& \vec{v}_{t}=\vec{v}+\frac{m_{s}}{M} \vec{g} \\
& \vec{v}_{t}^{\prime}=\vec{v}+\frac{m_{s}}{M} \vec{g}^{\prime}
\end{aligned}
$$

where $M=m_{s}+m_{t}$ and $\vec{g}=\vec{v}_{t}-\vec{v}_{s}$. Substituting equations (B5) into the energy equation results in the expression

$$
\mathrm{g}^{\prime}=\mathrm{g} \sqrt{1-\frac{2 \Delta}{\mathrm{g}^{2} \mu}}
$$

where $\mu=\left(m_{s} m_{t}\right) /\left(m_{s}+m_{t}\right)$ is the reduced mass. Also, from equations (B5a) and (B5b) the following relation is obtained:

$$
\vec{v}_{S}^{\prime}-\vec{v}_{S}=\frac{m_{t}}{M}\left(\vec{g}-\vec{g}^{\prime}\right)
$$

Since $\vec{v}_{S}=\vec{u}_{S}+\vec{c}_{S}$ and $\vec{v}_{S}^{\prime}=\vec{u}_{S}+\vec{c}_{S}^{\prime}$, the following expression is obtained:

$$
\vec{c}_{s}^{\prime}-\vec{c}_{s}=\frac{m_{t}}{M}\left(\vec{g}-\vec{g}^{\prime}\right)
$$




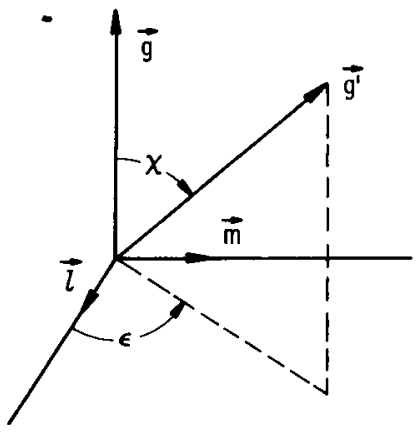

Figure 17. - Relation between relative velocities.

Considering figure 17 and using equation (B6) give the following relation:

$$
\begin{array}{r}
\vec{c}_{s}^{\prime}-\vec{c}_{s}=\frac{m_{t}}{M}\left(\vec{g}-\vec{g}^{\prime}\right)=\frac{m_{t}}{M}\left[\vec{g}\left(1-\sqrt{1-\frac{2 \Delta}{\mu g^{2}}} \cos \chi\right)\right. \\
\left.-g \sqrt{1-\frac{2 \Delta}{\mu g^{2}}} \sin \chi(\vec{\ell} \cos \epsilon+\vec{m} \sin \epsilon)\right]
\end{array}
$$

where $\vec{l}$ and $\overrightarrow{\mathrm{m}}$ are unit vectors. After substitution of equation (B7) into equation (B4), integration over $\epsilon$, if $\sigma$ is assumed to be independent of $\epsilon$, eliminates the $\vec{l}$ and $\overrightarrow{\mathrm{m}}$ components. As a result,

$$
\begin{aligned}
\int_{X=0}^{\pi} \int_{\epsilon=0}^{2 \pi}\left(\vec{c}_{S}-\vec{c}_{S}\right) \sigma_{d} \sin \chi d \chi d \epsilon & =2 \pi \frac{m_{t}}{M} \vec{g} \int_{X=0}^{\pi}\left(1-\sqrt{1-\frac{2 \Delta}{\mu g^{2}}} \cos \chi\right) \sigma_{d} \sin x d x \\
& =2 \pi \frac{m_{t}}{M} \vec{g} \sigma_{m}
\end{aligned}
$$

where the integral on the right side is the total momentum transfer cross section $\sigma_{\mathrm{m}}$. For elastic collisions, $\Delta=0$, and the elastic momentum transfer cross section is

$$
\sigma_{\mathrm{m} e \ell}(\mathrm{g})=2 \pi \int_{0}^{\pi}(1-\cos \chi) \sigma_{\mathrm{d}_{\mathrm{e} \ell}}(\mathrm{g}, \chi) \sin \chi \mathrm{d} \chi
$$

where $\sigma_{\mathrm{d}_{\mathrm{el}}}$ is the differential scattering cross section for elastic collisions.

For the inelastic processes, ionization and excitation, $\Delta=\mathrm{q} \varphi_{\mathrm{I}}$ or $\mathrm{q} \varphi_{\text {ex }}$, where $\varphi_{\mathrm{I}}$ is the ionization potential and $\varphi_{\mathrm{ex}}$ is the excitation potential (in volts). Since many levels may be excited, $\varphi_{\mathrm{ex}}$ and the differential cross section should be different for each level. Therefore, the complete expression for the total momentum transfer cross section is given as follows: 


$$
\begin{aligned}
& \sigma_{m}(g)=2 \pi \int_{0}^{\pi}(1-\cos x) \sigma_{d} \sin x d x \\
& +2 \pi \int_{0}^{\pi}\left(1-\sqrt{1-\frac{2 q \varphi_{I}}{\mu g^{2}}} \cos x\right) \sigma_{d_{I}} \sin x d x \\
& +\sum_{0}^{\pi}\left(1-\sqrt{1-\frac{2 q \varphi}{\mu x}} \cos x\right) \sigma_{d}^{2} \sin d x d x \\
& \sigma_{\mathrm{m}}=\sigma_{\mathrm{m}}+\sigma_{\mathrm{m}_{\mathrm{I}}}+\sum \sigma_{\mathrm{m}}
\end{aligned}
$$

where

$$
\sigma_{\mathrm{m}_{\mathrm{I}}}=2 \pi \int_{0}^{\pi}\left(1-\sqrt{1-\frac{2 \mathrm{q} \varphi_{\mathrm{I}}}{\mu \mathrm{g}^{2}}} \cos \chi\right) \sigma_{\mathrm{d}_{\mathrm{I}}} \sin \chi \mathrm{d} \chi
$$

and for each level

$$
\sigma_{\mathrm{m}}=2 \pi \int_{0}^{\pi}\left(1-\sqrt{1-\frac{2 \mathrm{q} \varphi \mathrm{ex}}{\mu \mathrm{g}^{2}}} \cos \chi\right) \sigma_{\mathrm{d}_{\mathrm{ex}}} \sin \chi \mathrm{d} \chi
$$

To determine a momentum transfer cross section, the differential cross section must be known. However, most experimental cross section measurements are of the total cross section, defined as

$$
\sigma_{T}(g)=2 \pi \int_{0}^{\pi} \sigma_{d} \sin \chi d \chi
$$

Experimental values of $\sigma_{\mathrm{T}_{\mathrm{el}}}, \sigma_{\mathrm{T}_{\mathrm{I}}}$, and $\sigma_{\mathrm{T}}$ as a function of electron energy for electron neutral collisions for several gases are presented in reference 7 (pp. 7, 102 and 111). Comparing the magnitudes of these quantities shows that, for electron energies $\left(=\frac{1}{2} \mathrm{~m}_{\mathrm{e}} \mathrm{v}_{\mathrm{e}}^{2}\right)$ 
- less than 25 electron volts, $\sigma_{\mathrm{T}_{\mathrm{e}}}$ is at least an order of magnitude greater than $\sigma_{\mathrm{T}_{\mathrm{I}}}$ and $\sigma_{\mathrm{T}}$. In reference 8 (p. 31), calculated values of $\sigma_{\mathrm{m}}$ are compared with $\sigma_{\mathrm{T}}$. Since $\sigma_{\mathrm{m}}$ and $\sigma_{\mathrm{T}}$ are of the same order, it would appear that the same conclusion that holds for $\sigma_{\mathrm{T}_{\mathrm{el}}}, \sigma_{\mathrm{T}_{\mathrm{I}}}$, and $\sigma_{\mathrm{T}}$ Nould also apply to $\sigma_{\mathrm{m}_{\mathrm{el}}}, \sigma_{\mathrm{m}_{\mathrm{I}}}$, and $\sigma_{\mathrm{m}}$, and as a result $\sigma_{\mathrm{m}_{\mathrm{I}}}$ and $\sigma_{\mathrm{m}}$ will be neglected compared with $\sigma_{\mathrm{m}}$ in equation (B9). In this case then, equation (B4) becomes

$$
\sum_{t} \int_{\vec{v}_{s}} m_{s} \vec{c}_{s}\left(\frac{\partial F_{s}}{\partial \tau}\right)_{t} d^{3} v_{s}=\sum_{t} \mu \int_{\vec{v}_{s}} \int_{\vec{v}_{t}} d^{3} v_{s} d^{3} v_{t} g \vec{g} F_{s} F_{t} \sigma_{m_{e l}}(g)
$$

The integration of equation (B10) has been performed by several authors (ref. 23) for the case where Maxwellian velocity distributions are assumed for $F_{S}$ and $F_{t}$. In this case the result is

$$
\begin{aligned}
\sum_{\mathrm{t}} \int_{\overrightarrow{\mathrm{v}}_{\mathrm{s}}} \mathrm{m}_{\mathrm{s}} \overrightarrow{\mathrm{c}}_{\mathrm{s}}\left(\frac{\partial \mathrm{F}_{\mathrm{s}}}{\partial \tau}\right)_{\mathrm{t}_{\mathrm{coll}}} \mathrm{d}^{3} \mathrm{v}_{\mathrm{s}}=-\sum_{\mathrm{t}} \frac{2 \mathrm{n}_{\mathrm{t}} \mathrm{s}^{\mu}}{\beta \pi^{1 / 2}} \frac{\overrightarrow{\mathrm{w}}}{\mathrm{w}^{2}} \mathrm{e}^{-\mathrm{w}^{2} / \beta^{2}} \int_{0}^{\infty} \mathrm{g}^{3} \sigma_{\mathrm{m}} \mathrm{el} \\
\times\left[\cosh \left(\frac{2 \mathrm{gw}}{\beta^{2}}\right)-\frac{\beta^{2}}{2 \mathrm{gw}} \sinh \frac{2 \mathrm{gw}}{\beta^{2}}\right] \mathrm{e}^{-\mathrm{g}^{2} / \beta^{2} \mathrm{dg}}
\end{aligned}
$$

where $\overrightarrow{\mathrm{w}}=\overrightarrow{\mathrm{u}}_{\mathrm{s}}-\overrightarrow{\mathrm{u}}_{\mathrm{t}}$ and $\beta^{2}=\left[\left(2 \mathrm{kT} \mathrm{s}_{\mathrm{s}} / \mathrm{m}_{\mathrm{s}}\right)+\left(2 \mathrm{kT} \mathrm{T}_{\mathrm{t}} / \mathrm{m}_{\mathrm{t}}\right)\right]$.

To carry out the $\mathrm{g}$ integration in equation (B11), $\sigma_{\mathrm{m}}$ (g) must be known. Even if the integration is performed, the result will be a function of both $\mathrm{w}$ and $\beta$, which is not a convenient form to be used in equation (B3); however, equation (B11) can be simplified for the case $w / \beta<<1$. For the Hall ion accelerator, this should be a good approximation in the case of electron-neutral and electron-ion collisions: 


$$
\frac{w}{\beta}=\left(\begin{array}{l}
\frac{u_{\mathrm{e}}-u_{\mathrm{i}}}{\sqrt{\frac{2 \mathrm{kT} \mathrm{T}_{\mathrm{e}}}{\mathrm{m}_{\mathrm{e}}}+\frac{2 \mathrm{kT}}{\mathrm{m}_{\mathrm{i}}}}} \\
\frac{\mathrm{u}_{\mathrm{e}}-\mathrm{u}_{\mathrm{o}}}{\sqrt{\frac{2 \mathrm{kT} \mathrm{T}_{\mathrm{e}}}{\mathrm{m}_{\mathrm{e}}}+\frac{2 \mathrm{kT} \mathrm{T}_{\mathrm{o}}}{\mathrm{m}_{\mathrm{o}}}}}
\end{array}\right) \approx \frac{\mathrm{u}_{\mathrm{e}}}{\sqrt{\frac{2 \mathrm{kT}_{\mathrm{e}}}{\mathrm{m}_{\mathrm{e}}}}} \approx \frac{\frac{\mathrm{E}_{\mathrm{z}}}{\mathrm{B}}}{\sqrt{\frac{2 \mathrm{kT} \mathrm{e}}{\mathrm{m}_{\mathrm{e}}}}}<\frac{10^{5}}{10^{6}}=0.1
$$

For the case $w / \beta \rightarrow 0$, equation (B11) becomes

$$
\sum_{\mathrm{t}} \int_{\overrightarrow{\mathrm{v}}_{\mathrm{s}}} \mathrm{m}_{\mathrm{s}} \overrightarrow{\mathrm{c}}_{\mathrm{s}}\left(\frac{\partial \mathrm{F}_{\mathrm{s}}}{\partial \tau}\right)_{\mathrm{t}} \mathrm{d}^{3} \mathrm{v}_{\mathrm{s}}=-\sum_{\mathrm{t}} \frac{8 \mathrm{n}_{\mathrm{s}} \mathrm{n}_{\mathrm{t}} \mu}{3 \pi^{1 / 2} \beta^{5}} \overrightarrow{\mathrm{w}}_{0}^{\infty} \mathrm{g}^{5} \sigma_{\mathrm{m}_{\mathrm{el}}}(\mathrm{g}) \mathrm{e}^{-\mathrm{g}^{2} / \beta^{2}} \mathrm{dg}
$$

Now the integral will be a function only of the parameter $\beta^{2}=\left(2 \mathrm{kT} \mathrm{s}_{\mathrm{S}} / \mathrm{m}_{\mathrm{s}}\right)+\left(2 \mathrm{kT} \mathrm{T}_{\mathrm{t}} / \mathrm{m}_{\mathrm{t}}\right)$. Equation (B12) can be written in terms of a momentum transfer collision frequency $\nu_{\text {st }}$ as follows

$$
\sum_{t} \int_{\vec{v}_{s}} m_{s} \vec{c}_{s}\left(\frac{\partial F_{s}}{\partial \tau}\right)_{t_{c o l l}} d^{3} v_{s}=-\sum_{t} \frac{m_{s} m_{t}}{m_{s}+m_{t}} n_{s} \nu_{s t_{m}}\left(\vec{u}_{s}-\vec{u}_{t}\right)
$$

where $\nu_{\text {st }_{\mathrm{m}}}$ is defined in the following way:

$$
\nu_{s t_{m}}=\frac{8 n_{t}}{3 \pi^{1 / 2}\left(\frac{2 k T_{s}}{m_{s}}+\frac{2 k T_{t}}{m_{t}}\right)^{5 / 2}} \int_{0}^{\infty} g^{5} \sigma_{m_{e l}}(g) e^{-g^{2} / \beta^{2}} d g
$$

Equation (B13) can be substituted into equation (B3) to obtain the equation of motion for the species $s$. The equation of motion for electrons in a plasma consisting of neutrals, singly charged ions, and electrons is 


$$
\dot{m}_{e}\left(\vec{u}_{e} \cdot \nabla\right) \vec{u}_{e}+\frac{\nabla p_{e}}{n_{e}}+q\left(\vec{E}+\vec{u}_{e} \times \vec{B}\right)=-\left[\frac{m_{e} m_{o}}{m_{e}+m_{o}} \nu_{e o}\left(\vec{u}_{e}-\vec{u}_{o}\right)+\frac{m_{e} m_{i}}{m_{e}+m_{i}} \nu_{e i}\left(\vec{u}_{e}-\vec{u}_{i}\right)\right]
$$

where a steady state has been assumed, and $\nabla \cdot \vec{\psi}=\nabla \mathrm{p}_{\mathrm{e}}$ since a Maxwellian velocity distribution has been assumed.

For the case of electron neutral collisions $\left(2 \mathrm{kT} \mathrm{T}_{\mathrm{e}} / \mathrm{m}_{\mathrm{e}}\right)+\left(2 \mathrm{kT} \mathrm{T}_{\mathrm{o}} / \mathrm{m}_{\mathrm{o}}\right) \approx\left(2 \mathrm{kT} \mathrm{T}_{\mathrm{e}} / \mathrm{m}_{\mathrm{e}}\right)$, and thus the electron neutral momentum transfer collision frequency is

$$
\nu_{\mathrm{eo}}=\frac{\mathrm{N}_{\mathrm{o}}}{3} \sqrt{\frac{2}{\pi}}\left(\frac{\mathrm{m}_{\mathrm{e}}}{\mathrm{kT}}\right)^{5 / 2} \int_{0}^{\infty} \mathrm{g}^{5} \sigma_{\mathrm{m}_{\mathrm{el}}}(\mathrm{g}) \mathrm{e}^{-\mathrm{m}_{\mathrm{e}} \mathrm{g}^{2} / 2 \mathrm{kT}} \mathrm{e} \mathrm{dg}
$$

In computing the integral in equation (B16), experimental values for $\sigma_{\mathrm{m}}$ (g) can be used. Since most of the experimental data is for cases where the neutral gas is initially at rest, the relative speed $g$ is essentially the electron speed $v_{e}$. In these cases it is convenient to write equation (B15) in terms of the electron energy, $\varphi=\frac{1}{2} \mathrm{~m}_{\mathrm{e}} \mathrm{v}_{\mathrm{e}}^{2}=\frac{1}{2} \mathrm{~m}_{\mathrm{e}^{\mathrm{g}}} \mathrm{g}^{2}$ in
volts:

$$
\nu_{\mathrm{eo}}=\frac{\mathrm{N}_{\mathrm{o}}}{3} \sqrt{\frac{32 \mathrm{q}}{\pi \mathrm{m}_{\mathrm{e}}\left(\frac{\mathrm{kT} \mathrm{e}}{\mathrm{q}}\right)^{5}}} \int_{0}^{\infty} \sigma_{\mathrm{m}_{\mathrm{el}}}(\varphi) \varphi^{2} \mathrm{e}^{-\mathrm{q} \varphi / \mathrm{kT}} \mathrm{e}_{\mathrm{d} \varphi}
$$

The total momentum transfer cross section for coulomb collisions can be computed analytically, provided that the lower limit in the expression

$$
\sigma_{m_{e \ell}}=2 \pi \int_{0}^{\pi}(1-\cos \chi) \sigma_{d} \sin \chi d \chi
$$

is cut off at some value, since the integral diverges at the lower limit in $\chi$. The value for $\sigma_{\mathrm{m}}$ when the integration is cut off at a lower limit corresponding to an impact parameter equal to the Debye distance, defined in mks units as 


$$
\mathrm{r}_{\mathrm{D}}=\left(\frac{\epsilon_{\mathrm{o}} \mathrm{kT}}{\sum_{\mathrm{s}} \mathrm{n}_{\mathrm{s}} \mathrm{q}_{\mathrm{s}}^{2}}\right)^{1 / 2}
$$

is given in reference 24 (p. 127) as

$$
\sigma_{m_{s t}}=4 \pi\left(\frac{\mathrm{q}_{\mathrm{s}} \mathrm{q}_{\mathrm{t}}}{4 \pi \epsilon{ }_{\mathrm{o}} \mu \mathrm{g}^{2}}\right)^{2} \ln \Lambda
$$

where $\epsilon_{o}$ is the permittivity of free space and $\Lambda=\frac{12 \pi \epsilon_{0} k T}{q_{s} q_{t}} r_{D^{*}}$. Burgers assumes thermal equilibrium $\left(T=T_{S}=T_{t}\right.$ ) in obtaining this result; however, for the Hall ion accelerator the electrons have a much higher temperature than the ions and neutrals. To compute $r_{D}$ and $\ln \Lambda$, therefore, $T_{e}$ will be used in the expressions for $r_{D}$ and $\Lambda$. Substituting the momentum transfer cross section in equation (B14) and assuming $\left(2 \mathrm{kT} \mathrm{T}_{\mathrm{e}} / \mathrm{m}_{\mathrm{e}}\right)>>\left(2 \mathrm{kT} \mathrm{T}_{\mathrm{i}} / \mathrm{m}_{\mathrm{i}}\right)$ give the following results for the electron-ion momentum transfer collision frequency

$$
\nu_{\mathrm{ei}_{\mathrm{m}}}=\frac{4 \sqrt{2 \pi}}{3}\left(\frac{\mathrm{q}^{2}}{4 \pi \epsilon_{\mathrm{o}}}\right)^{2} \frac{\mathrm{n}_{\mathrm{i}} \ln \Lambda}{\mathrm{m}_{\mathrm{e}}^{1 / 2}\left(\mathrm{kT}_{\mathrm{e}}\right)^{3 / 2}}=3.63 \times 10^{-6} \frac{\mathrm{n}_{\mathrm{e}} \ln \Lambda}{\mathrm{T}_{\mathrm{e}}^{3 / 2}} \quad \mathrm{sec}^{-1}(\mathrm{mks})
$$

where equal charge densities have been assumed $\left(n_{e}=n_{i}\right)$ and

$$
\Lambda=\frac{\left.12 \pi\left(\epsilon_{\mathrm{o}} \mathrm{kT}\right)_{\mathrm{e}}\right)^{3 / 2}}{\mathrm{q}^{3}\left(\mathrm{n}_{\mathrm{e}}\right)^{1 / 2}}=1.24 \times 10^{7} \sqrt{\frac{\mathrm{T}_{\mathrm{e}}^{3}}{\mathrm{n}_{\mathrm{e}}}} \quad(\mathrm{mks})
$$




\section{APPENDIX C}

\section{ELECTRON ENERGY EQUATION}

The energy equation for the species $s$ can be obtained by multiplying the Boltzmann equation by $\frac{1}{2} \mathrm{~m}_{\mathrm{s}} \mathrm{v}_{\mathrm{S}}^{2}$ and integrating over $\overrightarrow{\mathrm{v}}_{\mathrm{S}}$ with the following result (ref. 24, eq. (5-43), p. 132)

$$
\begin{aligned}
\frac{\partial}{\partial t}\left[m_{s} n_{s}\left(\frac{3}{2} \frac{p_{s}}{m_{s} n_{s}}+\frac{u_{s}^{2}}{2}\right)\right]+\nabla \cdot\left\{\vec{u}_{s}\left[m_{s} n_{s}\left(\frac{3}{2} \frac{p_{s}}{m_{s} n_{s}}+\frac{u_{s}^{2}}{2}\right)\right]\right\} \\
+\nabla \cdot \overrightarrow{\vec{\psi}}_{s} \cdot \vec{u}_{s}+\nabla \cdot \vec{Q}_{s}-q_{s} n_{s} \vec{E}_{s} \cdot \vec{u}_{s}=\sum_{t} \int_{\vec{v}_{s}}\left(\frac{\partial F_{s}}{\partial \tau}\right)_{t_{c o l l}} \frac{1}{2} m_{s} v_{s} d^{3} v_{s}
\end{aligned}
$$

where $\vec{Q}_{S}=\frac{1}{2} m_{S} \int_{\vec{v}_{S}} c_{S}^{2} \vec{c}_{S} F_{S} d^{3} v_{S}$ is the heat flow vector and $p_{S}=\frac{1}{3} m_{s} \int_{\vec{v}_{S}} c_{S}^{2} F_{S} d^{3} v_{S}$ is the scalar pressure. The term on the right side of equation (C1) represents the energy gained by species $\mathbf{s}$ in collisions with all other species.

Similar to the case for momentum transfer, the energy transfer term due to collisions can be written as follows:

$\sum_{t} \int_{\vec{v}_{S}}\left(\frac{\partial F_{s}}{\partial \tau}\right)_{t} \frac{1}{2} m_{\text {coll }}^{2} d^{3} v_{s}$

$$
=\sum_{t} \int_{\vec{v}_{S}} \int_{\vec{v}_{t}}^{\pi} \int_{x=0}^{2 \pi} \int_{\epsilon=0}^{3} d^{3} v_{S} d^{3} v_{t} \frac{m_{s}}{2}\left(v_{s}^{\prime 2}-v_{s}^{2}\right) F_{s} F_{t} g \sigma_{d}(g, x) \sin x d x d \epsilon
$$

Using equations (B5a), (B5b), and (B5c) gives the following results for $\left(v_{s}^{+2}-v_{s}^{2}\right)$ :

$$
\frac{1}{2} m_{s}\left(v_{s}^{2}-v_{s}^{2}\right)=\mu \vec{V} \cdot\left(\vec{g}-\vec{g}^{t}\right)-\frac{m_{t} \Delta}{M}
$$


Using equation (C3) in equation (C2) and performing the $X$ and $\epsilon$ integrations results in ..

$$
\begin{aligned}
& \sum_{t} \int_{\vec{v}_{s}}\left(\frac{\partial F_{s}}{\partial \tau}\right)_{t_{\text {coll }}} \frac{1}{2} m_{s} v_{s}^{2} d^{3} v_{s}=\sum_{t} \mu \int_{\vec{v}_{s}} \int_{\vec{v}_{t}} g \vec{v} \cdot \vec{g} \sigma_{m}(g) F_{s} F_{t} d^{3} v_{s} d^{3} v_{t} \\
& -\sum_{t}\left[\frac{m_{t} q \varphi_{I}}{M} \int_{\vec{v}_{S}} \int_{\vec{v}_{t}} g \sigma_{T_{I}}(g) F_{S} F_{t} d^{3} v_{S} d^{3} v_{t}\right. \\
& \left.+\sum \frac{m_{t} q \varphi \text { ex }}{M} \int_{\vec{v}_{s}} \int_{\vec{v}_{t}} g \sigma_{T_{e x}}(g) F_{s} F_{t} d^{3} v_{s} d^{3} v_{t}\right]
\end{aligned}
$$

where $\sigma_{\mathrm{T}_{\mathrm{i}}}$ and $\sigma_{\mathrm{T}}$ are the total ionization and excitation cross sections defined in appendix $\mathrm{B}$. As was done in appendix $\mathrm{B}, \sigma_{\mathrm{m}}$, the total momentum transfer cross section, will be approximated by the elastic total momentum transfer cross section.

To perform the $\vec{v}_{s}$ and $\vec{v}_{t}$ integrations a coordinate transformation will be made. Values for $F_{S}$ and $T_{t}$ must also be assumed, however. The most obvious approximation for $F_{s}$ and $F_{t}$ is a Maxwellian about the mean velocities $\vec{u}_{s}$ and $\vec{u}_{t}$ at the species temperatures $T_{s}$ and $T_{t}$. Therefore,

$$
\begin{aligned}
& F_{s}=\frac{n_{s}}{\pi^{3 / 2} a_{s}^{3}} e^{-\left(\frac{\vec{v}_{s}-\vec{u}_{s}}{a_{s}}\right)^{2}} \\
& F_{t}=\frac{n_{t}}{\pi^{3 / 2} a_{t}^{3}} e^{-\left(\frac{\vec{v}_{t}-\vec{u}_{t}}{a_{t}}\right)^{2}}
\end{aligned}
$$

where $\mathrm{a}_{\mathrm{s}}^{2}=2 \mathrm{kT} \mathrm{s}_{\mathrm{s}} / \mathrm{m}_{\mathrm{s}}$ and $\mathrm{a}_{\mathrm{t}}^{2}=2 \mathrm{kT} \mathrm{T}_{\mathrm{t}} / \mathrm{m}_{\mathrm{t}}$. The product of the distribution functions is transformed into the following expression 


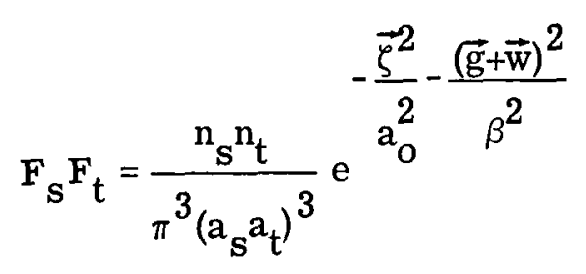

where the quantities appearing in this expression are defined as follows:

$$
\begin{gathered}
\vec{\zeta}=\vec{v}-\frac{a_{t}^{2} \vec{u}_{s}+a_{s}^{2} \vec{u}_{t}}{\beta^{2}}-\mathscr{T g} \\
\vec{w}=\vec{u}_{s}-\vec{u}_{t} \\
\beta^{2}=a_{s}^{2}+a_{t}^{2} \\
a_{o}^{2}=\frac{a_{s}^{2} a_{t}^{2}}{\beta^{2}} \\
\mathscr{T}=\frac{m_{t} a_{t}^{2}-m_{s} a_{s}^{2}}{M \beta^{2}}=\frac{2 k\left(T_{t}-T_{s}\right)}{M \beta^{2}}
\end{gathered}
$$

It is now possible to transform the integration in equation (C4) from $\vec{v}_{s}, \vec{v}_{t}$ to $\vec{\zeta}, \vec{g}$ since

$$
d^{3} v_{s} d^{3} v_{t}=|J| d^{3} \zeta d^{3} g=d^{3} \zeta d^{3} g
$$

where the Jacobian, $|J|=\frac{\partial\left(\overrightarrow{\mathrm{v}}_{\mathbf{S}}, \overrightarrow{\mathrm{v}}_{\mathrm{t}}\right)}{\partial(\overrightarrow{\mathrm{v}}, \overrightarrow{\mathrm{g}})} \frac{\partial(\overrightarrow{\mathrm{V}}, \overrightarrow{\mathrm{g}})}{\partial(\vec{\zeta}, \overrightarrow{\mathrm{g}})}=1$. The Jacobian is calculated by using equations (B5) and the definition of $\vec{\zeta}$. Substituting the product of the distribution functions in equation (C4) and integrating over $\vec{\zeta}$ result in 
$\sum_{\mathrm{t}} \int_{\overrightarrow{\mathrm{v}}_{\mathrm{S}}}\left(\frac{\partial \mathrm{F}_{\mathrm{S}}}{\partial \tau}\right)_{\mathrm{t}_{\text {coll }}} \frac{1}{2} \mathrm{~m}_{\mathrm{s}} \mathrm{v}_{\mathrm{S}}^{2} \mathrm{~d}^{3} \mathrm{v}_{\mathrm{S}}$

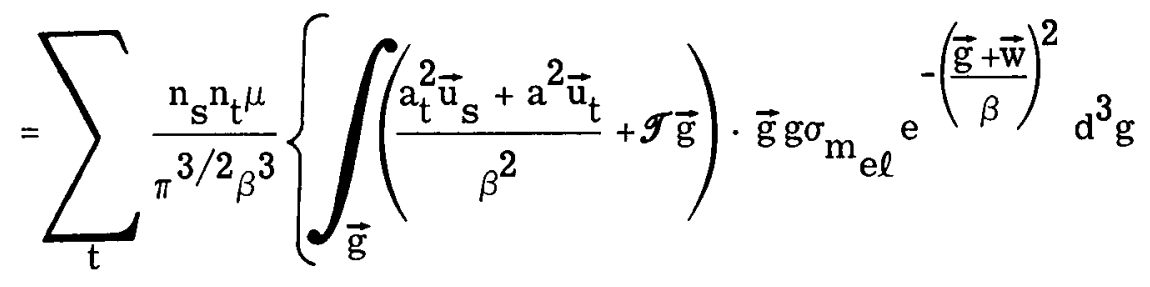

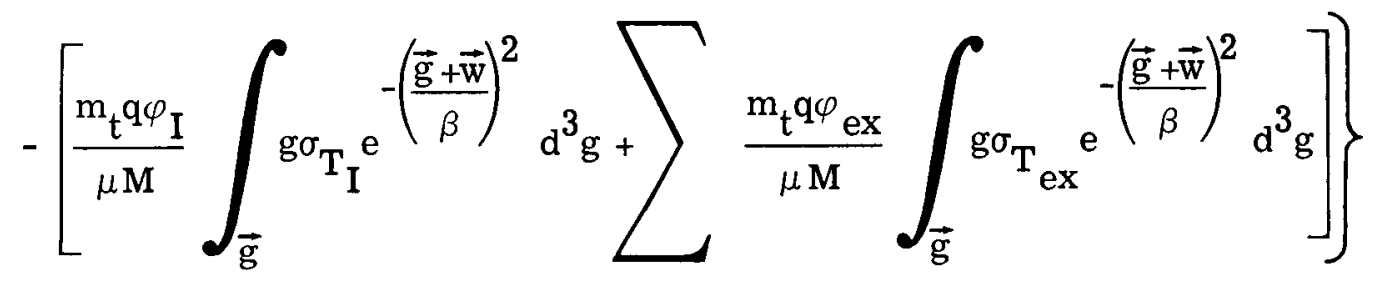

Changing the integrals to spherical coordinates and carrying out the angular integrations give

$$
\begin{aligned}
& \sum_{t} \int_{\vec{v}_{S}}\left(\frac{\partial F_{S}}{\partial \tau}\right)_{t} \frac{1}{2} m_{s^{v}} v_{S}^{2} d^{3} v_{S}=\sum_{t} \frac{2 n_{s} n_{t} \mu}{\pi^{1 / 2} \beta} \frac{1}{w} e^{-(w / \beta)^{2}}\left\{-\frac{\vec{w}}{w}\left(\frac{a_{t}^{2} \vec{u}_{S}+a^{2} \vec{u}_{t}}{\beta^{2}}\right)\right. \\
& \times \int_{0}^{\infty} \mathrm{g}^{3} \sigma_{\mathrm{m} e l}\left(\cosh \frac{2 \mathrm{gw}}{\beta^{2}}-\frac{\beta^{2}}{2 \mathrm{gw}} \sinh \frac{2 \mathrm{gw}}{\beta^{2}}\right) \mathrm{e}^{-\mathrm{g}^{2} / \beta^{2}} \mathrm{dg} \\
& +\mathscr{g} \int_{0}^{\infty} \mathrm{g}^{4} \sigma_{\mathrm{m}_{\mathrm{el}}} \sinh \left(\frac{2 \mathrm{gw}}{\beta^{2}}\right) \mathrm{e}^{-(\mathrm{g} / \beta)^{2}} \mathrm{dg}-\frac{\mathrm{m}_{\mathrm{t}}}{\mu \mathrm{M}}\left[\mathrm{q} \varphi_{\mathrm{I}} \int_{0}^{\infty} \mathrm{g}^{2} \sinh \frac{2 \mathrm{gw}}{\beta^{2}} \sigma_{\mathrm{T}_{\mathrm{I}}} \mathrm{e}^{-(\mathrm{g} / \beta)^{2}} \mathrm{dg}\right. \\
& \left.\left.+\sum \mathrm{q} \varphi \text { ex } \int_{0}^{\infty} \mathrm{g}^{2} \sinh \frac{2 \mathrm{qw}}{\beta^{2}} \sigma_{\mathrm{T}} \mathrm{ex}^{-(\mathrm{g} / \beta)^{2}} \mathrm{dg}\right]\right\}
\end{aligned}
$$


- Just as in the case for momentum transfer (appendix B), the limit $w / \beta \rightarrow 0$ is taken. As a result the first integral vanishes:

$$
\begin{aligned}
\sum_{\mathrm{t}} & \int_{\overrightarrow{\mathrm{v}}_{\mathrm{s}}}\left(\frac{\partial \mathrm{F}_{\mathrm{s}}}{\partial \tau}\right)_{\mathrm{t}_{\text {coll }}} \frac{1}{2} \mathrm{~m}_{\mathrm{s}} \mathrm{v}_{\mathrm{s}}^{2} \mathrm{~d}^{3} \mathrm{v}_{3}=\sum_{\mathrm{t}} \frac{4 \mathrm{n}_{\mathrm{s}} \mathrm{n}_{\mathrm{t}}}{\pi^{1 / 2} \beta^{3}}\left\{\mu \int_{0}^{\infty} \mathrm{g}^{5} \sigma_{\mathrm{m}_{\mathrm{el}}} \mathrm{e}^{-(\mathrm{g} / \beta)^{2}} \mathrm{dg}\right. \\
& \left.-\frac{\mathrm{m}_{\mathrm{t}}}{\mathrm{M}}\left[\mathrm{q} \varphi_{\mathrm{I}} \int_{0}^{\infty} \mathrm{g}^{3} \sigma_{\mathrm{T}_{\mathrm{I}}} \mathrm{e}^{-(\mathrm{g} / \beta)^{2}} \mathrm{dg}+\sum^{\mathrm{q} \varphi} \mathrm{ex} \int_{0}^{\infty} \mathrm{g}^{3} \sigma_{\mathrm{T}_{\mathrm{ex}}} \mathrm{e}^{-(\mathrm{g} / \beta)^{2}} \mathrm{dg}\right]\right\}
\end{aligned}
$$

Equation (C7) can be written in terms of the momentum transfer collision frequency, an ionization collision frequency, and an excitation collision frequency

$$
\begin{aligned}
\sum_{\mathrm{t}} & \int_{\overrightarrow{\mathrm{v}}_{\mathrm{s}}}\left(\frac{\partial \mathrm{F} \mathrm{s}}{\partial \tau}\right)_{\mathrm{t}_{\text {coll }}} \frac{1}{2} \mathrm{~m}_{\mathrm{s}} \mathrm{v}_{\mathrm{s}}^{2} \mathrm{~d}^{3} \mathrm{v}_{\mathrm{s}} \\
& =\sum_{\mathrm{t}} \mathrm{n}_{\mathrm{s}}\left[\frac{3 \mathrm{~m}_{\mathrm{s}} \mathrm{m}_{\mathrm{t}}}{\left(\mathrm{m}_{\mathrm{s}}+\mathrm{m}_{\mathrm{t}}\right)^{2}}\left(\mathrm{kT}_{\mathrm{t}}-\mathrm{kT}_{\mathrm{s}}\right) \nu_{\mathrm{st}}-\frac{\mathrm{m}_{\mathrm{t}}}{\mathrm{m}_{\mathrm{t}}+\mathrm{m}_{\mathrm{s}}}\left(\mathrm{q} \varphi_{\mathrm{I}}^{\nu} \mathrm{st}_{\mathrm{I}}+\sum \mathrm{q} \varphi_{\mathrm{ex}}{ }_{\mathrm{st}}\right)\right]
\end{aligned}
$$

where $v_{\mathrm{st}}$ is defined by equation (B14) and

$$
\begin{gathered}
\nu_{\text {st }_{\mathrm{I}}}=\frac{4 \mathrm{n}_{\mathrm{t}}}{\pi^{1 / 2} \beta^{3}} \int_{\mathrm{g}_{\mathrm{i}}}^{\infty} \mathrm{g}^{3} \sigma_{\mathrm{T}_{\mathrm{I}}}(\mathrm{g}) \mathrm{e}^{-\mathrm{g}^{2} / \beta^{2}} \mathrm{dg} \quad \sigma_{\mathrm{T}_{\mathrm{I}}}=0 \text { for } \mathrm{g}<\mathrm{g}_{\mathrm{i}} \\
\nu_{\text {st }}=\frac{4 \mathrm{n}_{\mathrm{t}}}{\pi^{1 / 2} \beta^{3}} \int_{\mathrm{g}_{\mathrm{ex}}}^{\infty} \mathrm{g}^{3} \sigma_{\mathrm{T}_{\mathrm{ex}}}(\mathrm{g}) \mathrm{e}^{-\mathrm{g}^{2} / \beta^{2}} \mathrm{dg} \quad \sigma_{\mathrm{T}_{\mathrm{ex}}}=0 \text { for } \mathrm{g}<\mathrm{g}_{\mathrm{ex}}
\end{gathered}
$$

Substituting equation (C8) into equation (C1) gives the energy equation for species s: 


$$
\begin{aligned}
\frac{\partial}{\partial t}\left[m_{s} n_{s}\left(\frac{3}{2} \frac{p_{s}}{m_{s} n_{s}}+\frac{u_{s}^{2}}{2}\right)\right]+\nabla \cdot\left\{\vec{u}_{s}\left[m_{s} n_{s}\left(\frac{3}{2} \frac{p_{s}}{m_{s} n_{s}}+\frac{u_{s}^{2}}{2}\right)\right]\right\}+\nabla \cdot\left(p_{s} \vec{u}_{s}\right)-q_{s} n_{s} \vec{E} \cdot \vec{u}_{s} \\
=\sum_{t} n_{s}\left[\frac{3 m_{s} m_{t}}{\left(m_{s}+m_{t}\right)^{2}}\left(k T_{t}-k^{\prime} T_{s}\right) \nu_{s t}-\frac{m_{t}}{m_{t}+m_{s}}\left(q \varphi_{I} \nu_{s t}+\sum q \varphi e x_{s t} \nu_{e x}\right)\right]
\end{aligned}
$$

It should be noted that, since a Maxwellian velocity distribution function has been assumed, the heat flow vector vanishes and that $\nabla \cdot\left(\vec{\psi}_{\mathbf{s}} \cdot \overrightarrow{\mathrm{u}}_{\mathrm{s}}\right)=\nabla \mathrm{p}_{\mathrm{s}} \overrightarrow{\mathrm{u}}_{\mathbf{s}} \cdot$ Consider now the form equation (C11) takes for electrons in a plasma made up of electrons, singly charged ions, and neutrals of the same species as the ions. For ionization and excitation of neutrals by electron impact, equations (C9) and (C10) in terms of the electron energy in volts, become

$$
\nu_{\mathrm{eo}_{\mathrm{I}}} \equiv \nu_{\mathrm{I}}=\frac{8}{\sqrt{\pi}}\left(\frac{\mathrm{q}}{\mathrm{m}_{\mathrm{e}}}\right)^{2}\left(\frac{\mathrm{m}_{\mathrm{e}}}{2 \mathrm{kT}}\right)^{3 / 2} \int_{\varphi_{\mathrm{I}}}^{\infty} \mathrm{N}_{\mathrm{o}} \sigma_{\mathrm{T}_{\mathrm{I}}}(\varphi) \varphi \mathrm{e}^{-\mathrm{q} \varphi / \mathrm{kT}} \mathrm{e} \mathrm{d} \varphi
$$

and

$$
\nu_{\mathrm{eo}} \equiv \nu_{\mathrm{ex}}=\frac{8}{\sqrt{\pi}}\left(\frac{\mathrm{q}}{\mathrm{m}_{\mathrm{e}}}\right)^{2}\left(\frac{\mathrm{m}_{\mathrm{e}}}{2 \mathrm{k} \mathrm{T}_{\mathrm{e}}}\right)^{3 / 2} \int_{\varphi_{\mathrm{ex}}}^{\infty} \mathrm{N}_{\mathrm{o}} \sigma_{\mathrm{T}_{\mathrm{ex}}}(\varphi) \varphi \mathrm{e}^{-\mathrm{q} \varphi / \mathrm{kT}} \mathrm{e} \mathrm{d} \varphi
$$

where;

$$
\varphi=\frac{1}{2} \frac{\mathrm{m}}{\mathrm{q}} \mathrm{g}^{2}
$$

In deriving the preceding results, the condition, $\mathrm{T}_{\mathrm{e}} / \mathrm{m}_{\mathrm{e}} \gg \mathrm{T}_{\mathrm{o}} / \mathrm{m}_{0}$ has been used to obtain $\beta^{2}=2 \mathrm{kT} \mathrm{e}^{/ \mathrm{m}_{\mathrm{e}}}$. The ionization collision frequency $\nu_{\mathrm{I}}$ for electron-neutral collisions is obtained by carrying out the indicated integration of $\sigma_{\mathrm{T}_{\mathrm{I}}}$. A useful expression for $\nu_{\mathrm{I}}$ is obtained at low temperatures by assuming $\sigma_{\mathrm{T}_{\mathrm{I}}}$ to be the following linear func-
tion of $\varphi$

$$
\left(\mathrm{N}_{\mathrm{o}}\right)_{\mathrm{std}} \sigma_{\mathrm{T}}=\mathrm{a}_{\mathrm{I}}\left(\varphi-\varphi_{\mathrm{I}}\right)
$$


where $a_{I}$ is a constant, $\varphi_{I}$ is the ionization potential, and $\left(N_{o}\right)_{s t d}$ is the number density at $0^{\circ} \mathrm{C}$ and 1 millimeter of mercury $\left(133.3 \mathrm{~N} / \mathrm{m}^{2}\right)$. Such a linear approximation for the ionization cross section is made in reference 6 . Therefore, for an arbitrary number density $\mathrm{N}_{\mathrm{O}}$ (in reciprocal cubic meters) equation (C14) becomes

$$
\mathrm{N}_{\mathrm{o}} \sigma_{\mathrm{T}_{\mathrm{I}}}=\mathrm{a}_{\mathrm{I}} \mathrm{p}_{\mathrm{o}}\left(\varphi-\varphi_{\mathrm{I}}\right) \frac{273}{\mathrm{~T}_{\mathrm{o}}}
$$

where $T_{0}$ is the neutral temperature in ${ }^{\circ} \mathrm{K}$ and $\mathrm{p}_{\mathrm{O}}$ is the neutral pressure in newtons per square meter. In reference 11, von Engel gives values of $a_{I}$ for several gases when $\mathrm{p}_{\mathrm{o}}$ is measured in millimeters of mercury and $\mathrm{N}_{\mathrm{o}} \sigma_{\mathrm{T}}$ in reciprocal centimeters; hence,

$$
a_{I}=\frac{10^{2}}{133.3 \mathrm{~N} / \mathrm{m}^{2}}\left(a_{\mathrm{I}}\right)_{\mathrm{v} . \text { Engel }}=0.751 \frac{(\mathrm{m})\left(\mathrm{sec}^{2}\right)}{\mathrm{kg}}\left(\mathrm{a}_{\mathrm{I}}\right)_{\mathrm{v} . \text { Engel }}
$$

For argon,

$$
\left(\mathrm{a}_{\mathrm{I}}\right)_{\mathrm{v} . \text { Engel }}=0.71
$$

hence

$$
a_{I}=0.534(A)\left(\mathrm{sec}^{5}\right) /\left(\mathrm{kg}^{2}\right)\left(\mathrm{m}^{2}\right)
$$

Substituting equation (C15) in equation (C12) and integrating yield for small $\mathrm{T}_{\mathrm{e}}$

$$
\begin{aligned}
\nu_{\mathrm{I}} & =\frac{2}{\sqrt{\pi}} \frac{\mathrm{m}_{\mathrm{e}}}{\mathrm{q}} \mathrm{a}_{\mathrm{I}} \frac{273 \mathrm{p}_{\mathrm{o}}}{\mathrm{T}_{\mathrm{o}}}\left(\frac{2 \mathrm{kT} \mathrm{e}}{\mathrm{m}_{\mathrm{e}}}\right)^{3 / 2}\left(1+\frac{\mathrm{q} \varphi_{\mathrm{I}}}{2 \mathrm{kT}}\right) \mathrm{e}^{-\mathrm{q} \varphi_{\mathrm{I}} / \mathrm{kT}} \mathrm{e} \\
& =5.04 \times 10^{-15} \mathrm{a}_{\mathrm{I}} \mathrm{N}_{\mathrm{o}}\left(\frac{\mathrm{kT} \mathrm{e}}{\mathrm{q}}\right)^{3 / 2} \mathrm{e}^{-\mathrm{q} \varphi_{\mathrm{I}} / \mathrm{kT}} \mathrm{e}\left(1+\frac{\mathrm{q} \varphi_{\mathrm{I}}}{2 \mathrm{kT}}\right) \mathrm{sec}^{-1}
\end{aligned}
$$

where

$\mathrm{N}_{\mathrm{O}} \quad$ neutral number density, $\mathrm{m}^{-3}$ 
$\mathrm{T}_{\mathrm{o}} \quad$ neutral temperature, ${ }^{\mathrm{O}} \mathrm{K}$

$\mathrm{p}_{\mathrm{O}} \quad$ neutral pressure, $\mathrm{N} / \mathrm{m}^{2}$

$\varphi_{\mathrm{I}} \quad$ ionization potential of gas (for argon, $15.76 \mathrm{~V}$ ), $\mathrm{V}$

To obtain a low temperature approximation for the electron neutral excitation collision frequency, a linear variation of $\sigma_{\mathrm{T}}$ with electron energy will be made, just as was done in the case of the ionization collision frequency. Only the first atomic level is considered. For argon, the data of Druyvesteyn and Penning (ref. 7, p. 102) were used to construct an expression similar to equation (C15). As a result, an expression of the same form as equation (C17) is obtained

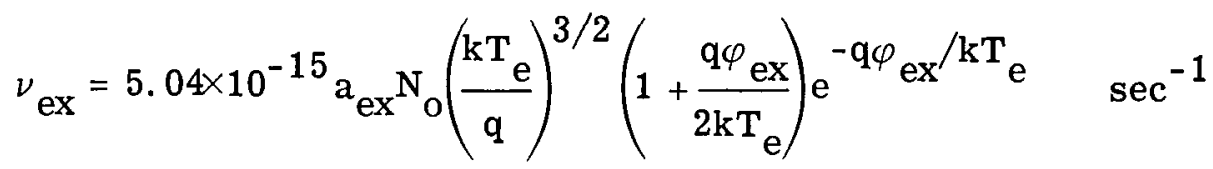

where

$\varphi_{\mathrm{ex}} \quad$ excitation potential of first level (for argon, 11.6 V), V

$a_{\text {ex }}$ defined the same way as $a_{I}$ in equation (C14); for argon,

$$
\mathrm{a}_{\mathrm{ex}}=0.251(\mathrm{~A})\left(\mathrm{sec}^{5}\right) /(\mathrm{kg})\left(\mathrm{m}^{2}\right)
$$

Sovie and Dugan (ref. 25) have calculated the quantity $\mathrm{q}\left(\varphi_{\mathrm{I}} \nu_{\mathrm{I}}+\sum \varphi_{\mathrm{ex}}{ }_{\mathrm{ex}}\right) / \mathrm{N}_{\mathrm{o}}$ for argon, cesium, and helium as a function of electron temperature. To calculate $\nu_{I}$ and $\nu_{\text {ex }}$, they assumed a Maxwellian distribution for the electrons and used the method of Gryzinski (ref. 26) to calculate ionization and excitation cross sections. Their results are compared in figure 18 with values of

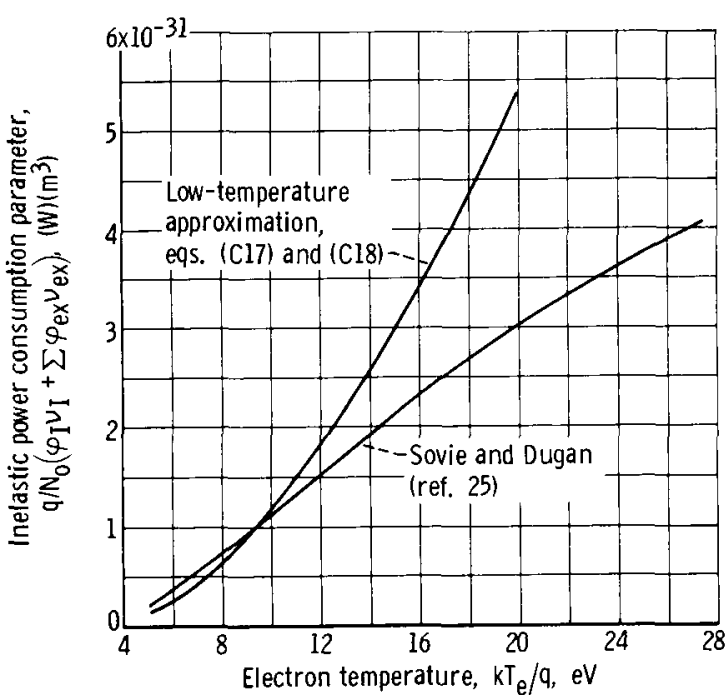

Figure 18. - Inelastic power consumption for Argon as a function of electron temperature. $\mathrm{q}\left(\varphi_{\mathrm{ex}} \nu_{\mathrm{ex}}+\varphi_{\mathrm{I}} \nu_{\mathrm{I}}\right) / \mathrm{N}_{\mathrm{O}}$ for argon calculated by using equations (C17) and (C18). Reasonable agreement is obtained for low values of the electron temperature. At an electron temperature of 14 electron volts, the results of reference 25 and the calculated values begin to diverge as a result of the assumed linear variation of $\sigma_{\text {ex }}$ and $\sigma_{I}$ with electron energy made in deriving $\nu_{\mathrm{I}}$ and $\nu_{\mathrm{ex}}$. However, below 14 electron volts, the calculated values are within 20 percent of the results in reference 25 . For low temperatures, either evaluation of this inelastic loss parameter is equally justifiable. At high temperatures, the values calculated in reference 25 are more accurate. 


\section{REFERENCES}

1. Seikel, G. R. ; and Reshotko, E.: Hall Current Ion Accelerator. Bull. Am. Phys. Soc., ser. II, vol. 7, no. 6, June 1962, p. 414.

2. Hess, R. V. : Experiments and Theory for Continuous Steady Acceleration of Low Density Plasmas. Vol. 1 of Proc. XIth Int. Astronau. Conf., Springer-Verlag (Berlin), 1961, pp. 404-411.

3. Salz, F.; Meyerand, R. G., Jr.; and Lary, E. C. : Ion Acceleration in a GyroDominated Neutral Plasma Experiment. Bull. Am. Phys. Soc., ser. II, vol. 7, no. 7, Aug. 1962, p. 441.

4. Janes, G. S. ; Dotson, J. ; and Wilson, T. : Momentum Transfer Through Magnetic Fields. Vol. 1 of Advanced Prop. Concepts, Gordon and Breach Sci. Pub., Inc., 1963, pp. 153-175.

5. Cann, Gordon L. ; and Marlotte, Gary L. : Hall Current Plasma Accelerator. AIAA J. , vol. 2, no. 7, July 1964, pp. 1234-1241.

6. Lehnert, B. : Diffusion Processes in the Positive Column in a Longitudinal Magnetic Field. Vol. 32 of Proc. Second Int. Conf. on Peaceful Uses of Atomic Energy, United Nations, Geneva, pp. 349-357.

7. Brown, S. C. : Basic Data of Plasma Physics. Technology Press, M. I. T., 1959.

8. Janes, G. S. ; and Dotson, J. : Experimental Studies of Oscillations and Accompanying Anomalous Electron Diffusion Occurring in D. C. Low Density Hall Type Crossed Field Plasma Accelerators. Proc. Fifth Symposium on Eng. Aspects of Magnetohydrodynamics, M.I. T., Apr. 1-2, 1964, pp. 135-148.

9. Brockman, Philip; Hess, Robert V.; and Weinstein, Richard: Measurements and Theor etical Interpretation of Hall Currents for Steady Axial Discharges in Radial Magnetic Fields. Paper No. 63-382, AIAA, 1963.

10. Yoshikawa, S. ; and Rose, D. J.: Anomalous Diffusion of a Plasma Across a Magnetic Field. Phys. Fluids, vol. 5, no. 3, Mar. 1962, pp. 334-340.

11. von Engel, A. : Ionized Gases. Clarendon Press (Oxford), 1955.

12. Domitz, Stanley: Experimental Evaluation of a Direct-Current Low-Pressure Plasma Source. NASA TN D-1659, 1963.

13. Boyd, R. L. F.; and Twiddy, N. D. : Electron Energy Distributions in Plasmas. Proc. Roy. Soc. (London), ser. A, vol. 250, no. 1260, Feb. 24, 1959, pp. 53-69. 
14. Garscadden, A.; and Emeleus, K. G. : Notes on the Effect of Noise on Langmuir Probe Characteristics. Proc. Phys. Soc. (London), vol. 79, pt. 3, Mar. 1962, pp. 535-541.

15. Glasstone, S. ; and Lovberg, R. H. : Controlled Thermonuclear Reactions. D. Van Nostrand Co., Inc., 1960, pp. 194-198.

16. Abramowitz, Milton; and Stegun, Irene A., eds.: Handbook of Mathematical Functions with Formulas, Graphs, and Mathematical Tables. AMS 55, NBS, 1964.

17. Bohm, D.: The Characteristics of Electrical Discharges in Magnetic Fields, A. Guthrie and R. K. Wakerling, eds., McGraw-Hill Book Co., Inc., 1949, chs. I; III.

18. Bates, D. R.; Kingston, A. E.; and McWhirter, R. W. P.: Recombination Between Electrons and Atomic Ions. I. Optically Thin Plasmas. Proc. Roy. Soc. (London), ser. A, vol. 267, no. 1329, May 8, 1962, pp. 297-312.

19. McDaniel, E. W.: Collision Phenomena in Ionized Gases. John Wiley \& Sons, Inc., 1964.

20. Tonks, Lewi; and Langmuir, Irving: A General Theory of the Plasma of an Arc. Phys. Rev., vol. 34, no. 6, Sept. 15, 1929, pp. 876-922.

21. Spitzer, L.: Physics of Fully Ionized Gases. Second ed., Intersci. Pub., 1962.

22. Chapman, S. ; and Cowling, T. G.: The Mathematical Theory of Nonuniform Gases. Cambridge Univ. Press, 1960.

23. Morse, T. F.: Energy and Momentum Exchange Between Nonequipartition Gases. Phys. Fluids, vol. 6, no. 10, Oct. 1963, pp. 1420-1427.

24. Burgers, J. M. : Statistical Plasma Mechanics. Ch. 5 of Symposium on Plasma Dynamics, F. H. Clauser, ed., Addison-Wesley Pub. Co., Inc., 1960.

25. Sovie, Ronald J. ; and Dugan, John V. : Energy Required for Ion Production by Electron Bombardment in Helium, Argon, and Cesium. Paper presented at Gaseous Electronics Conf., Am. Phys. Soc., Atlantic City (N.J.), Oct. 14-16, 1964. (See also NASA TM X-52064, 1964.)

26. Gryzinski, Michal: Classical Theory of Electronic and Ionic Inelastic Collisions. Phys. Rev., vol. 115, no. 2, July 15, 1959, pp. 374-383. 
"The aeronautical and space activities of the United States shall be conducted so as to contribute. . . to the expansion of buman knowledge of pbenomena in the atmospbere and space. The Administration shall provide for the widest practicable and appropriate dissemination of information concerning its activities and the results thereof."

\section{NASA SCIENTIFIC AND TECHNICAL PUBLICATIONS}

TECHNICAL REPORTS: Scientific and technical information considered important, complete, and a lasting contribution to existing knowledge.

TECHNICAL NOTES: Information less broad in scope but nevertheless of importance as a contribution to existing knowledge.

TECHNICAL MEMORANDUMS: Information receiving limited distribution because of preliminary data, security classification, or other reasons.

CONTRACTOR REPORTS: Technical information generated in connection with a NASA contract or grant and released under NASA auspices.

TECHNICAL TRANSLATIONS: Information published in a foreign language considered to merit NASA distribution in English.

TECHNICAL REPRINTS: Information derived from NASA activities and initially published in the form of journal articles.

SPECIAL PUBLICATIONS: Information derived from or of value to NASA activities but not necessarily reporting the results of individual NASA-programmed scientific efforts. Publications include conference proceedings, monographs, data compilations, handbooks, sourcebooks, and special bibliographies.

Defails on the availability of these publicotions may be obtained from:

SCIENTIFIC AND TECHNICAL INFORMATION DIVISION

NATIONAL AERONAUTICS AND SPACE ADMINISTRATION

Washington, D.C. 20546 